\title{
Principles and Techniques of Eyelid Reconstruction
}

\author{
Francesco Bernardini and Brent Skippen
}

\section{Principles of Periocular Reconstruction}

The end goal of eyelid reconstruction is both functional and aesthetic restoration of the eyelid and periocular area while minimizing surgical morbidity. Attention to reconstruction of the bilamellar eyelid structure is essential [1]. Reconstructive surgical planning is determined by several factors including the nature of the defect, the health and age of the patient, the availability and integrity of surrounding tissues, and the surgeon's experience and preferences.

A preoperative consultation is mandatory to determine possible sites from which flaps and grafts may be obtained to minimize surgical morbidity [1].

In general, the following principles help achieve successful eyelid and periorbital reconstruction [2]:

1. If both anterior and posterior eyelid lamellae are to be reconstructed, only one can consist

Electronic supplementary material The online version of this chapter (https://doi.org/10.1007/978-3-030-187576_4) contains supplementary material, which is available to authorized users.

F. Bernardini $(\bowtie)$

Oculoplastica Bernardini, Genoa, Italy

e-mail: francesco@oculoplasticabernardini.it

\section{B. Skippen}

Department of Ophthalmology, Wagga Wagga Rural

Referral Hospital, Wagga Wagga, NSW, Australia of a graft, the other must be composed of a vascularized flap. Graft on graft reconstruction has a high failure probability because of lack of vascular supply.

2. Aim to provide adequate canthal fixation to support the reconstructed eyelid/globe apposition.

3. Provide sufficient horizontal and vertical eyelid dimensions for maximal function, i.e., avoid vertical tension on the lower eyelid.

4. Perform any appropriate direct closure of the defect prior to sizing a graft.

5. Match tissue characteristics as best as possible for grafts and flaps.

6. Balance complexity of technique(s) with improvement(s) in outcome.

7. Eyelid closure adequate to avoid exposure sequelae.

8. Optimal eyelid symmetry and cosmesis (tissue of appropriate color, texture, and thickness).

\section{Box 4.1 General Principles}

- Recognize full-thickness vs. anterior lamella defects

- Anterior lamella defects:

- Always prefer primary closure with or without undermining

- Flaps over grafts

- Grafts possibly from eyelid skin when available

- Full-thickness skin grafts (FTSGs) to the eyelids and canthus require 
ideally a thinner than those used on other areas of the face. Thankfully, the periocular region is wellvascularized, with typically excellent wound healing.

- Small to medium size full-thickness defects of the lower lid can usually be repaired by direct closure, adding canthotomy and cantholysis or semicircular Tenzel flap if necessary.

- Larger defects (>50\%) are usually repaired in at least two layers (posterior and anterior lamella) using flaps or grafts.

- Medial canthal defects are more challenging to repair to preserve the lacrimal system function.

- Lateral canthal defects can also have particular challenges.

Note: Some general principles are useful to guide the progression in eyelid reconstruction, from basic to more advance.

\section{Reconstruction of Eyelid Defects}

The type of surgery depends upon extent of tissue removed.

\section{Preferred Anesthesia}

For most surgeries the anesthesia used is the same:

- Local anesthesia with propofol sedation

- 27G-30G needle, $1 \%$ ropivacaine or $0.5 \%$ bupivacaine with 1:100,000 adrenaline

Basic instruments and necessary equipment are shown in Fig. 4.1.

\section{Anterior Lamella Defects}

Partial thickness anterior lamellar defects can be left to heal by secondary intention if small [3]. Larger defects may warrant direct closure or a simple sliding flap or graft to avoid rota-

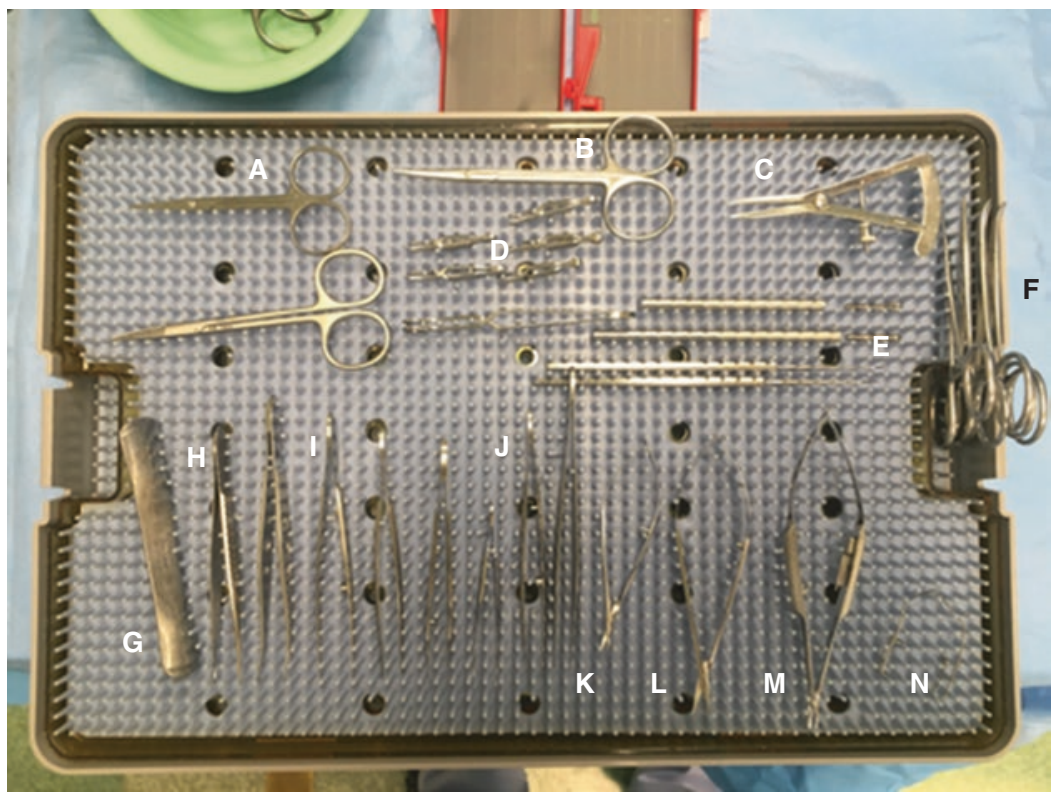

Fig. 4.1 Basic instruments and necessary equipment. A, iris (straight, sharp-tipped) scissors; B, Stevens (curved, blunt-tipped) scissors; C, surgical calipers; D, bulldog clamps; E, skin retractors, single and double pronged; F, artery forceps, curved; G, Jaeger lid plate; H, small fine- tooth tissue forceps; I, small, non-tooth forceps; J, large tooth forceps (Adson); K, Vannas spring scissors, curved; L, Westcott tenotomy scissors, curved; M, Castroviejo needle holder, with catch; $\mathrm{N}$, eyelid speculum 
tion of the eyelashes. Options for reconstruction of partial thickness periocular defects include:

1. Laissez-faire (small): Healing by secondary intention or granulation

2. Topical imiquimod 5\% for 1 month

3. Direct closure

4. Flap or graft

- Flaps: e.g., transposition, advancement, rotation, bilobed, rhomboid, z-plasty, V-Y plasty, Y-V plasty

- Grafts: Full-thickness skin graft, splitthickness skin graft

\section{Laissez-Faire}

Laissez-faire is also known as healing by secondary intention or granulation. Fox and Beard described their good results following healing by secondary intention in six medial canthal defects [4]. Mehta reported 11 cases of satisfactory healing by secondary intention with defects involving the lower lid and medial canthus [5]. Da Costa and Jones described one patient having an excellent outcome following excision of a lateral canthal lesion [6]. Da Costa and Jones also showed that the technique of laissez-faire can be extended to larger defects with a good outcome [6]. One patient in their series had an excellent functional and aesthetic outcome following healing of a large upper eyelid defect.

Shankar et al. reported a series of 25 periocular defects with healing by secondary intention [7]. A "good" or "very good" result was obtained in $92 \%$ of their cases. Only one patient required secondary surgery for cicatricial ectropion [7]. A patient satisfaction survey in their study showed high patient satisfaction with the aesthetic outcome and postoperative follow-up required for healing by laissez-faire.

Indications for a laissez-faire approach to periocular skin tumors also include [8]:

1. Medial canthal lesions, especially after radiotherapy, where the skin may be unsuitable for flaps or free skin grafts.
2. Patients with primary skin precancerous conditions like xeroderma pigmentosa.

3. Patients with poor general health, who may not be fit for general anesthesia or prolonged surgical procedures involving complex skin flaps or skin grafting under local anesthesia.

4. For tumor surveillance where detection of tumor recurrences beneath or adjacent to the reconstructed area may be delayed.

5. Simplicity of wound management for patient care associated with this technique [7].

6. Also, in cases of large defects that are closed partially with flaps and grafts but not entirely, a small part of the defect can be left to heal by secondary intention.

7. Not indicated in patients with poor compliance for follow-up.

\section{Disadvantages of Laissez-Faire Include}

1. Prolonged healing time

2. Small risk of a secondary surgical intervention

3. Causing lower lid cicatricial ectropion and subsequent watery eye

4. Poor suitability for large upper lid defects where there may the risk of exposure keratitis during wound healing

\section{Direct Closure}

Direct closure may be useful for both partial and full-thickness eyelid defects following tumor excision. The immediate postoperative distortion is temporary thanks to spontaneous tissue expansion brought about by the steady pressure of the displaced globe against the reconstructed eyelid [9]. The surgery is often simple and the functional and cosmetic results can be excellent. In the event of histologically incomplete tumor resection, subsequent re-excision for additional clearance would not present the problems that other reconstructive techniques might. Should postoperative wound dehiscence occur, the defect may be allowed to granulate as in the "laissez-faire" method. Subsequent 
excision of any notch or delayed reconstruction would still be viable options and made easier by the decrease in defect size [9].

The factors that make direct closure possible are [9]:

1. Preexisting eyelid and canthal tendon laxity.

2. Inherent eyelid elasticity.

3. Straightening of the normal lid curvature (arc to chord conversion) by globe displacement.

4. The "mechanical tissue creep" phenomenon talked of in relation to tissue expander use under the skin [10].

5. Mechanical creep is one of the factors that makes direct closure under tension possible (Fig. 4.2).

Although the operated eyelid may be under considerable tension at the end of surgery, as long as the tension is horizontal, it usually relaxes within a matter of days without running the risk of eyelid malposition [9]. Generally, by 2 months postoperatively, the eyelid has expanded to normal proportions.

\section{Full-Thickness Skin Graft}

Indication for Surgery Skin grafting is a relatively easy procedure that any reconstructive surgeon should master before undertaking tumor excision. Even though the best functional and aesthetic results are achievable with local flaps, there are occasions where a skin graft is the best option as in cases of elongated oval-shaped central eyelid defects (Fig. 4.3). In the eyelid region, skin grafting means full-thickness skin graft (FTSG). FTSGs are best when harvested from the upper eyelid skin when available; other potential donor areas include the preauricular or postauricular areas, inner brachial, and supraclavicular areas. When harvesting FTSGs from areas other than the upper eyelid, there are some disadvantages include the potential for color/thickness mismatch; risk of potential complications such as graft contracture, scar hypertrophy, and more rarely graft failure. Figure $4.3 \mathrm{c}$ demonstrates the use of a bolster associated with Frost sutures to improve graft survival and overall better graft uptake. It is always a good idea to use a firm pressure dressing for $48-72 \mathrm{~h}$.
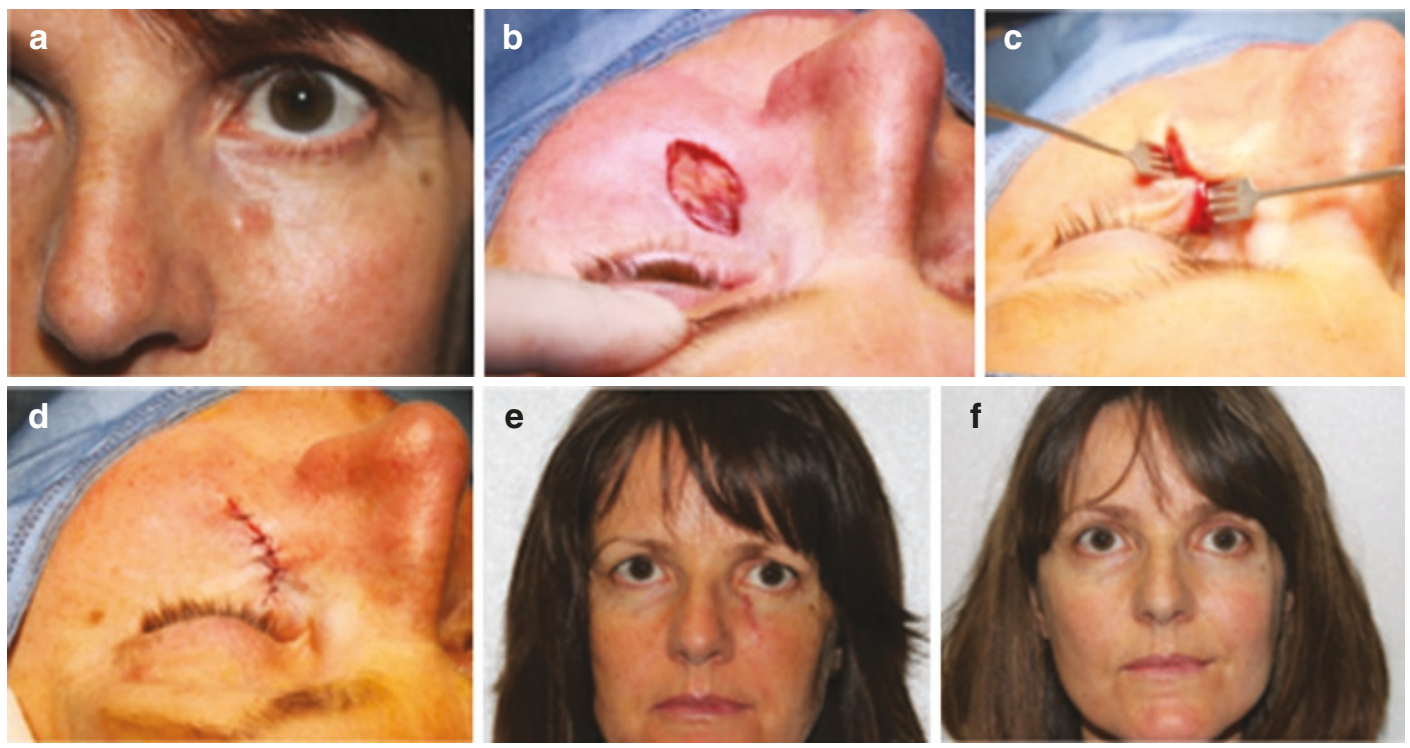

Fig. 4.2 (a-f) Direct closure of a lower lid-cheek junction defect 

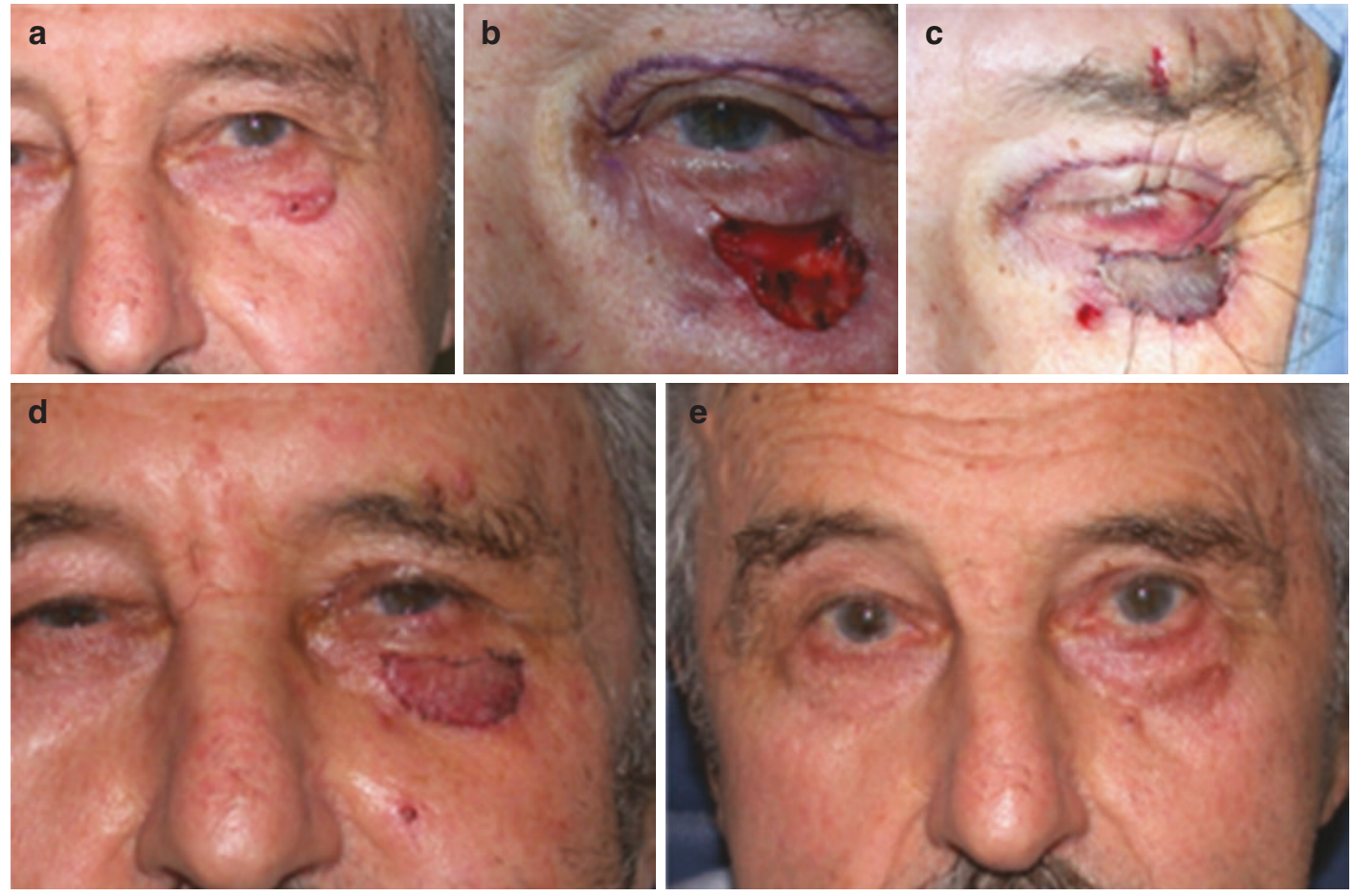

Fig. 4.3 (a-e) Upper lid full-thickness skin graft for closure of lower lid-cheek junction defect

\section{Standard Surgical Technique}

- A template is used to measure the size of the defect and match to the area being harvested.

- The FTSG is harvested, taking care not to button-hole the tissue.

- The FTSG is then thinned posteriorly, using Westcott scissors to remove subcutaneous tissue.

- The thinned graft is then secured to the defect, first using 3-4 cardinal sutures of 6-0 Vicryl.

- The rest of the graft is sutured into place using 7-0 Vicryl which can be used in an interrupted or continuous fashion.

- A bolster associated with longer Frost sutures to keep it in place may assist graft survival (Fig 4.3c).

- A firm pressure dressing should be used for 48-72 $\mathrm{h}$ whether or not the bolster was used (Fig. 4.3).

\section{Full-Thickness Defects (Anterior Lamella and Posterior Lamella)}

Full-thickness eyelid defects require reconstruction of both the anterior and posterior lamellae. Both lamellae can't be grafts since at least one of them must have a blood supply. The correct options include:

1. Anterior graft + posterior flap $\mathrm{OR}$

2. Anterior flap + posterior graft $\mathrm{OR}$

3. Anterior + posterior flap

\section{Upper Lid Full-Thickness Defect}

The surgeon's choice depends upon extent of tissue removed and especially upon the horizontal extent of the defect (Table 4.1).

Two major factors determining the repair are the horizontal extent of the defect and how much 
Table 4.1 Treatment of full-thickness upper eyelid defect

\begin{tabular}{l|l}
\hline $\begin{array}{l}\text { Horizontal defect } \\
\text { \% of total lid } \\
\text { length) }\end{array}$ & Surgical options \\
\hline$<33 \%$ & Direct closure \\
\hline $33-66 \%$ & $\begin{array}{l}\text { Lateral cantholysis } \\
\text { Tenzel semicircular flap }\end{array}$ \\
\hline$>66 \%$ & $\begin{array}{l}\text { Full thickness lower to upper } \\
\text { eyelid flap repair, e.g., Cutler- } \\
\text { Beard procedure } \\
\end{array}$ \\
& $\begin{array}{l}\text { 2 stages, divide at 2-6 weeks } \\
\text { Posterior lamella defect: } \\
\text { graft-opposite tarso- } \\
\text { conjunctiva, ear, palate } \\
\text { Cannot use if other eye has poor } \\
\text { vision } \\
\text { Periosteal strip } \\
\text { Anterior lamella advancement } \\
\text { from upper lid + posterior lamella } \\
\text { graft (2 stage) } \\
\text { "Bucket handle" flap } \\
\text { Sliding upper eyelid } \\
\text { tarsoconjunctival flap } \\
\text { Mustarde total lid switch }\end{array}$ \\
\hline
\end{tabular}

tarsal plate remains [3]. Repair of the upper eyelids is more important than the lower as it is the upper eyelid that is the main protector of the cornea during blinking and eye closure [3]. Once an upper eyelid defect can no longer be closed by direct suture, tissue must be added back to the eyelid, and there have been numerous techniques described including full-thickness flaps and grafts from the surrounding tissues (including the lower eyelid); anterior lamella advancement, sliding, and rotational flaps; and combined upper and lower lid advancement flaps. Numerous grafts have been described including skin, mucous membrane, hard palate, nasal mucosa, and auricular cartilage [3].

Depending on the laxity of the eyelid tissues, full-thickness defects of the eyelid margin involving up to one-third of the horizontal length may be closed with direct closure. Residual tension can be released with a lateral canthotomy or cantholysis [11]. Direct closure of a wound affecting one-third to two-thirds of the eyelid may be done if there is enough horizontal laxity of the eyelid. If the wound is too tight, then a canthotomy and cantholysis should be consid- ered [3]. If the temporal skin can be mobilized, then a semicircular advancement (Tenzel) flap technique can be utilized [12]. If the lateral canthus has been lost, then a local tarsoconjunctival flap may be used along with a periosteal strip [13, 14]. The anterior lamella can be replaced with a full-thickness skin graft or myocutaneous flap. If there is enough anterior lamella to support a graft, then alternatives may be used to recreate the posterior lamella, such as a free tarsal graft from the contralateral upper eyelid or hard palate.

When there is insufficient local upper eyelid tissue to reconstruct the full-thickness defect, distal flaps must be constructed to provide a blood supply for any reconstruction. The classic upper eyelid reconstruction when more than two-thirds of the eyelid is missing is a Cutler-Beard procedure, which is a two-stage bridging procedure [11].

\section{Direct Closure}

Indication for Surgery. For smaller defects of the upper eyelids, the same principles of repair for a lower eyelid apply to the upper. The amount of upper eyelid tissue that can be excised with direct closure to follow is generally $8-10 \mathrm{~mm}$ (up to $50 \%$ ), but this depends on the age of the patient and the degree of eyelid laxity. Assessment includes pulling the edges of the defect together to confirm the wound is not under too much tension [3].

In selected cases, direct eyelid closure may be achieved after considerably larger eyelid margin resections than conventionally taught. The immediate postoperative distortion and reduction in palpebral aperture (ptosis) is temporary thanks to spontaneous tissue expansion brought about by the steady pressure of the displaced globe against the reconstructed eyelid. The surgery is simple and the functional and cosmetic results are excellent [15].

\section{Standard Surgical Technique}

- 7-0 polygalactin (Vicryl) sutures placed in the tarsus, gray line to gray line with a vertical mattress suture; a slight eversion of the wound edges is desirable to avoid the risk of notching of the eyelid margin (Fig 4.4b). 

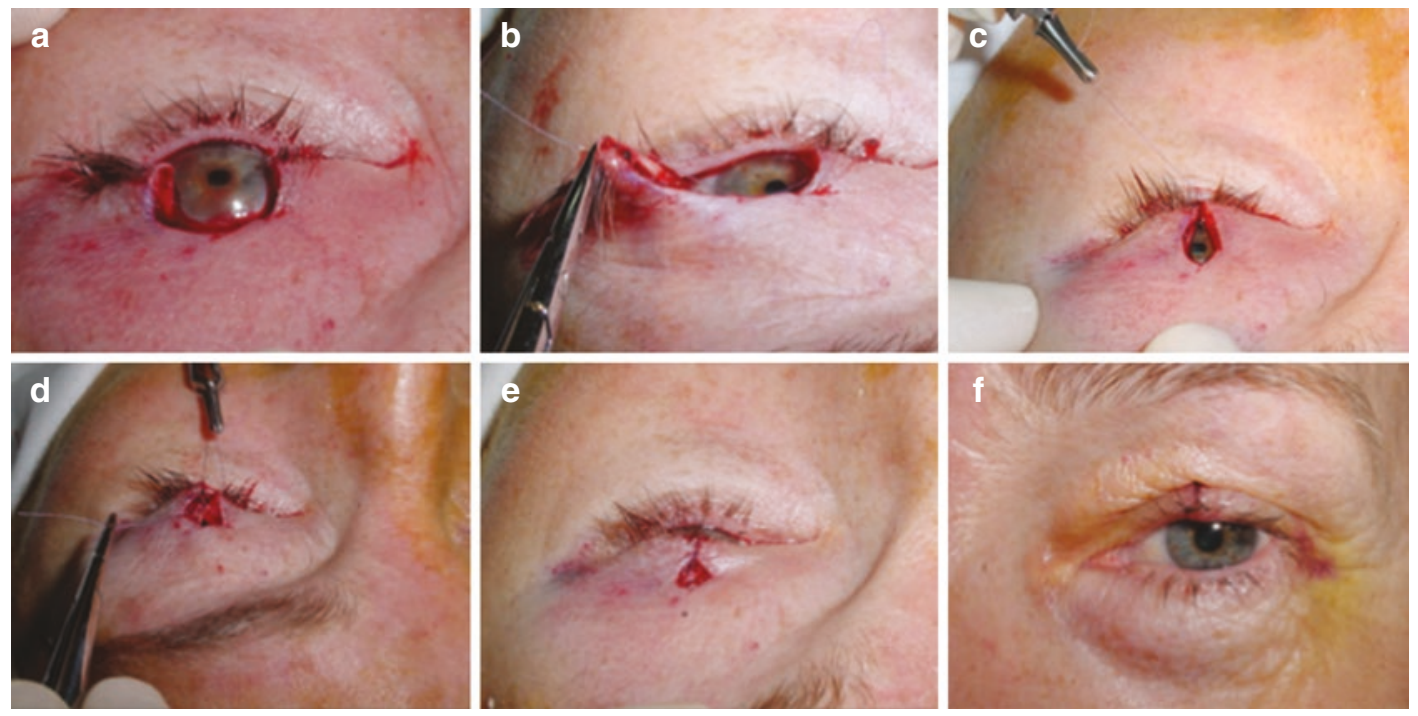

Fig. 4.4 (a-f) Direct closure of a full-thickness upper eyelid wound 33-50\% horizontal length

- A second 7-0 Vicryl suture is used to approximate the anterior lash line.

- Two to three deep tarsal sutures are passed partial thickness through the tarsal plate to take the horizontal tension off the eyelid marginone close to the eyelid margin and a second parallel and 1-2 mm from the first (Fig. 4.4c).

- Skin sutures are then placed in an interrupted or continuous fashion, using 7-0 Vicryl (Fig 4.4f).

\section{Lateral Semicircular Skin Flap or Tenzel Flap}

Indication for Surgery. The amount of skin flap that is rotated into the upper eyelid may be small as the main benefit of this procedure is the undermining of tissue lateral to the canthus, reducing the horizontal tension from direct eyelid advancement. The goal of the rotation flap is to use the skin lateral to the canthus to form the lateral eyelid and to mobilize the residual eyelid tissues centrally in contact with the eye. In elderly patients with more extensive upper eyelid tumors, rather than submitting the patient to a more complicated procedure, the superior limb of the medial canthal tendon can also be released [3].

Standard surgical technique (applicable for upper and lower eyelids) (see also surgical details for Tenzel flap reconstruction of the lower lid):
- First assess the eyelid tension to exclude the ability to close the defect via direct closure.

- A semicircular incision is marked out with a surgical marking pen starting at the lateral canthus, curving inferiorly for approximately $3 \mathrm{~cm}$ and laterally for approximately $2 \mathrm{~cm}$, or as much as possible taking care to remain within the lateral orbital rim with the semicircular flap dissection or less than $2 \mathrm{~cm}$ passed the rim to avoid injuring the frontal branch of the temporalis nerve (Fig 4.5b).

- The skin incision is made using a number 15 Bard Parker blade (Fig 4.5c).

- The flap is then undermined using blunttipped Stevens scissors to the depth of the mid-dermis (Fig 4.5d).

- A canthotomy and cantholysis are usually also required [16].

- The lateral canthus is suspended to the lateral orbital rim periosteum with a buried 5-0 Vicryl.

- The primary defect is closed first by way of simple primary closure followed by the repair of the semicircular defect. 6-0 Vicryl can be used, tarsal plate first and then lash line and anterior lamella.

- The lateral angle is then reformed fixating the rotated skin to the upper eyelid right at the corner. 

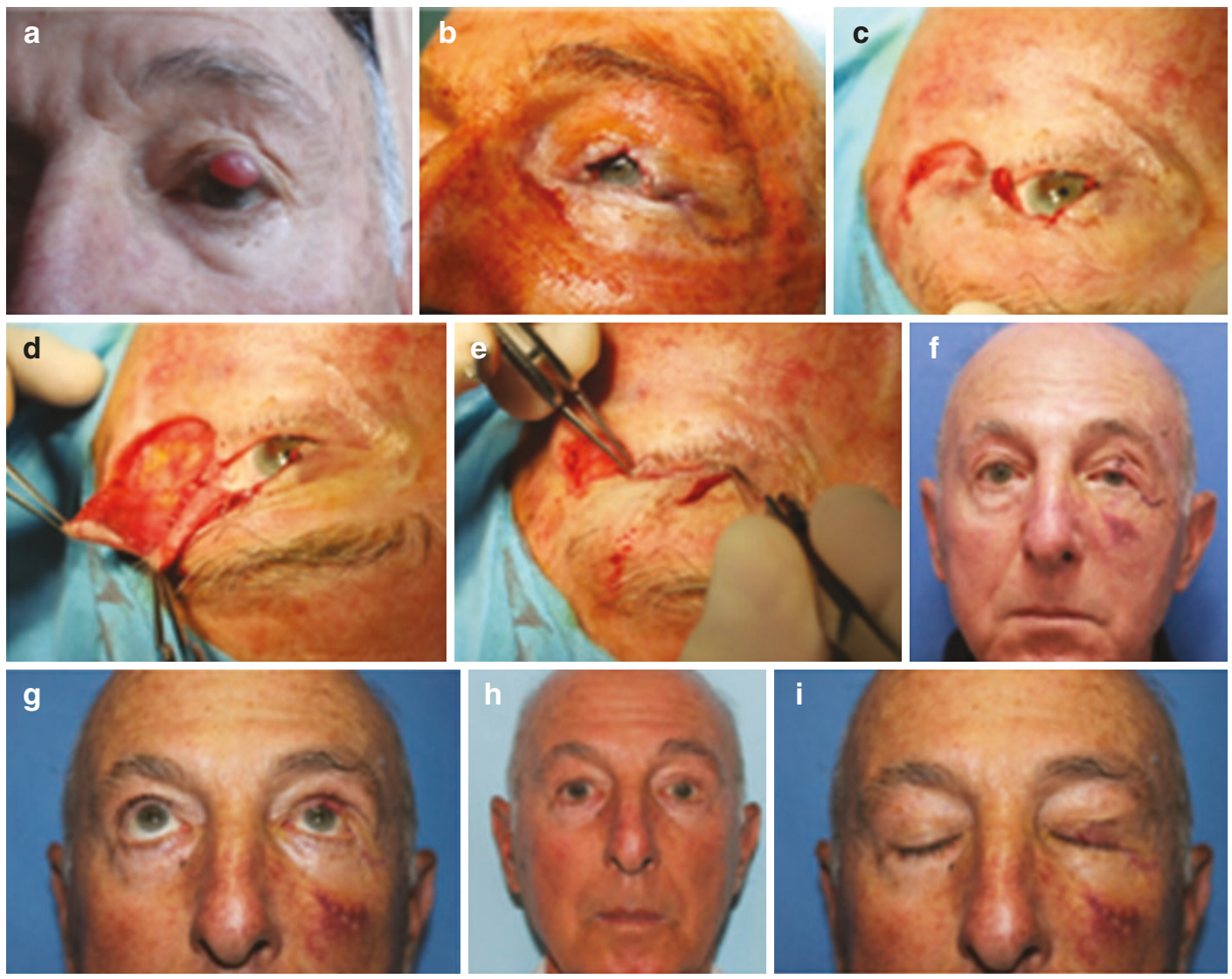

Fig. 4.5 (a-i) Tenzel semicircular flap repair of an upper eyelid defect

\section{Full-Thickness Lower to Upper Eyelid Flap Repair}

Indication for Surgery. The Cutler-Beard procedure uses a full-thickness advancement flap from the lower eyelid [13]. The method is only useful for vertical defects of the upper eyelid. Unfortunately, there is minimal to no tarsus added to the new upper lid margin, which is where the structural support is required and consequently upper lid entropion may result. Despite some postoperative problems, the Cutler-Beard procedure continues to be used by many surgeons and can be used for defects of $100 \%$ of the horizontal eyelid length [7] (Fig. 4.6).

\section{Standard Surgical Technique}

- The lower eyelid margin is left intact with inferior full-thickness incision made to advance a skin-muscle conjunctiva into the

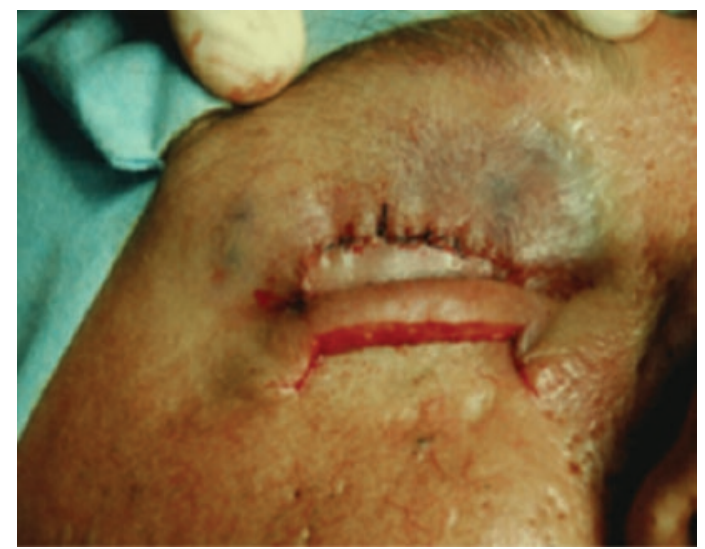

Fig. 4.6 End of stage 1 of Cutler-Beard procedure

upper eyelid underneath this bridge of tissue.

- A three-sided inverted U-shaped incision is marked on the lower eyelid using a surgical 
marking pen, beginning $4-5 \mathrm{~mm}$ below the eyelid margin [16].

- A silk traction suture is passed through the gray line of the lower eyelid, which is then everted over a Desmarres retractor.

- A conjunctival incision is made below the tarsus.

- A conjunctival flap is created and dissected inferiorly into the lower fornix and onto the globe.

- A free tarsal graft is harvested from the contralateral upper eyelid and sutured to the tarsal remnants and to the upper fornix conjunctiva and the lower edge of the levator muscle.

- The flap is advanced into the upper eyelid defect and sutured to the free tarsal graft using 6-0 Vicryl sutures, taking care to bury the knots to avoid corneal irritation.

- The edges of the graft are sutured edge to edge to either tarsal remnants or to local periosteal flaps using 5-0 Vicryl sutures [16].

- An incision is then made horizontally through the lower eyelid skin and orbicularis muscle just inferior to the tarsus and extended inferiorly to create a skin-muscle advancement flap [16].

- The lower eyelid skin-muscle flap is advanced posterior to the bridge of lower lid tarsal and eyelid margin tissue to cover the graft and sutured to the residual upper eyelid skin using 6-0 Vicryl sutures [16].

\section{Postoperative Medications and Wound Care: Pattern of Follow-Up Visits and Evaluation}

- Antibiotic ointment applied to wound and in the eye (check for allergies), firm double pad.

- Remove pad at home after $48 \mathrm{~h}$ and apply antibiotic ointment three times a day to wound.

- Follow-up in 1-2 weeks.

- The flap is divided 2-8 weeks after reconstruction with repair of the lower eyelid donor site and repair of the new eyelid margin to prevent entropion [11].

- Earlier division of the flap at 2 weeks has been reported without problem except in large defects or when the lower lid skin is tight such as in younger patients [17].

- For patients with a poor vascular supply (e.g., post-radiotherapy treatment or trauma), a longer interval between primary surgery and flap division is more suitable.

\section{Periosteal Strip: Adjunct Procedure}

Indication for Surgery. A strip of periosteum can be reflected from the zygoma nasally to function as a lateral canthal tendon and posterior lamella of the temporal eyelid. This is a useful adjunct procedure for larger upper eyelid defects $>66 \%$ of horizontal eyelid length.

Note: This is an adjunctive procedure to help with some eyelid reconstruction but not a standalone posterior lamella substitute.

\section{Standard Surgical Technique}

- After the lateral orbital rim is exposed with blunt dissection, a rectangular periosteal strip with an intact base is fashioned with a scalpel blade and separated from bone with a Freer elevator.

- The periosteal incisions are slanted $45^{\circ}$ downward for upper eyelid reconstructions so that the strip follows the contour of the upper eyelid after it is reflected superonasally.

- The strip should be at least $1 \mathrm{~cm}$ wide and long enough to reach the residual tarsal stump with adequate tension.

- The strip is reflected nasally to position the outer periosteum against the globe and sutured to the anterior surface of the residual tarsal stump with 5-0 polygalactin 910 (Vicryl) sutures.

- The anterior lamella needs to then be reconstructed by advancing a myocutaneous flap or FTSG over the strip.

- Residual conjunctiva in the fornix is sutured to the inferior edge of the strip with 7-0 polygalactin 910 sutures, and the side of the strip facing the eye is allowed to re-epithelialize.

\section{Bucket-Handle Flap}

Indication for Surgery. This has been described as a solution for reconstruction of total or semitotal full-thickness upper eyelid defects which is both relatively simple and utilizes well the potential vascularity of the transferred tissue [18]. This flap is also useful in patients with compromised healing abilities [18]. 


\section{Standard Surgical Technique [18]}

- A free tarsal graft is harvested from the contralateral upper eyelid and sutured to the remnants of the tarsal plate medially and laterally (Fig 4.7d). In case of a shortage of residual tarsal plate, a periosteal flap can be formed and used to anchor the free tarsal graft.

- The conjunctiva from the upper fornix is advanced and sutured to the upper tarsal border, as is the levator muscle (Fig 4.7e).

- A bucket handle bipedicle flap of orbicularis muscle and eyelid skin from just below the brow hair is transferred onto the lower edge of the upper eyelid defect to cover a free tarsal graft harvested from the contralateral upper eyelid (Fig 4.7f).

- The superior limb of the incision is made along the margin of the inferior brow with a number 15 Bard Parker blade with a horizontal extension as to adapt to fill the defect.

- The inferior limb of the incision corresponds to the upper edge of the eyelid defect.

- The medial and lateral ends of the flap are flared slightly to maximize the blood supply at each end of the flap.

- The flap is raised in the sub-orbicularis plane of dissection until it is mobile enough to allow for tension-free insertion into the upper eyelid defect.

- A FTSG is then harvested, possibly from the contralateral upper eyelid skin, and sutured to cover the sub-brow anterior lamella defect (Fig. 4.7g, h). Video 4.1- Reconstruction with free tarsal graft and flap.
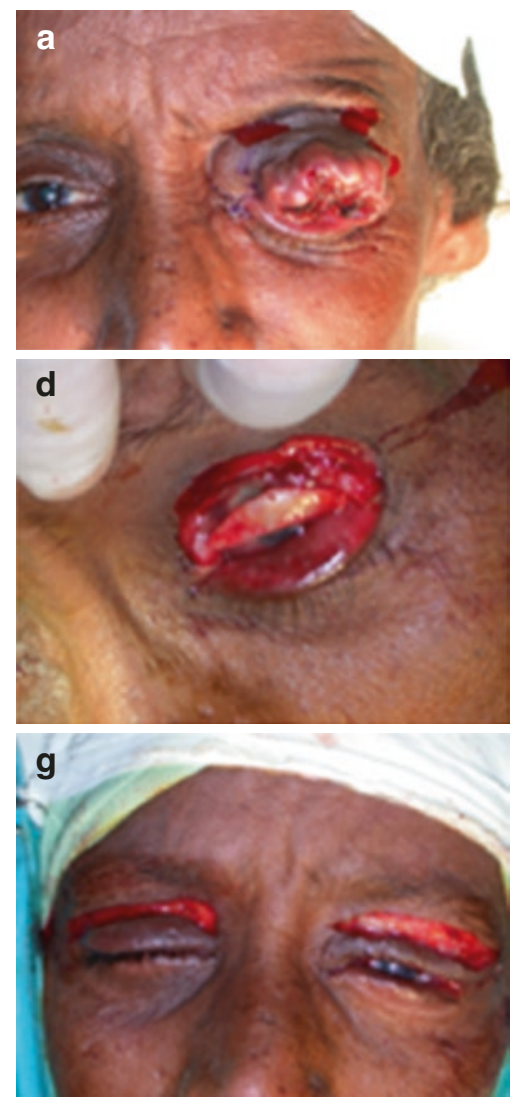
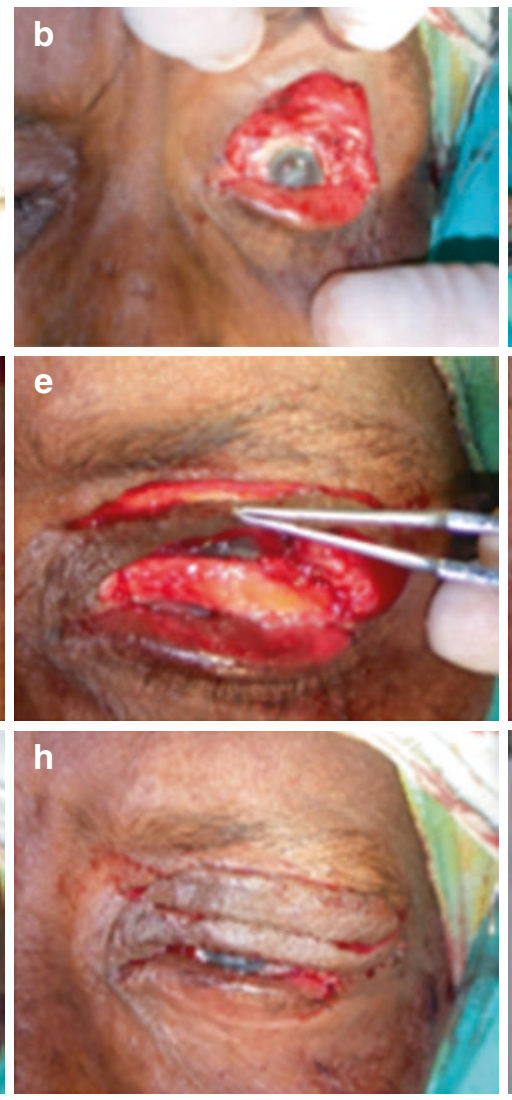
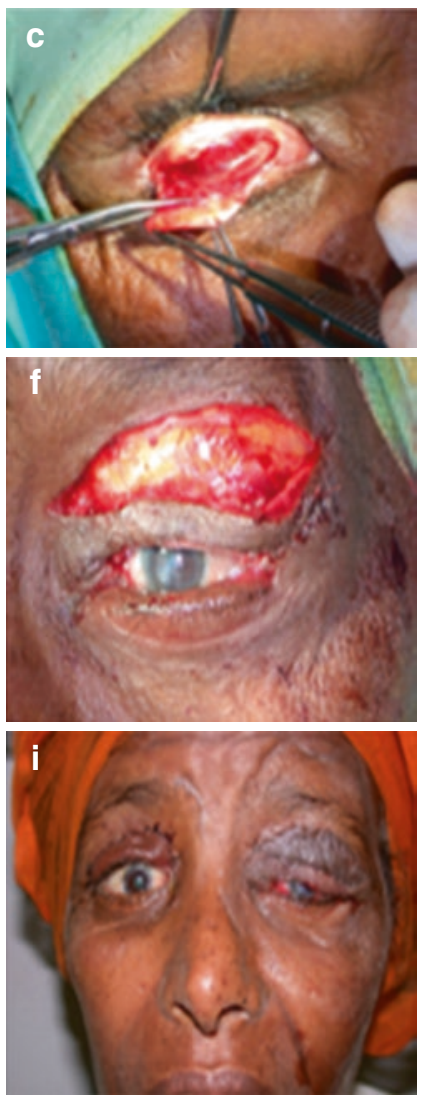

Fig. 4.7 (a-i) Bucket handle flap for left upper eyelid reconstruction 


\section{Postoperative Medications and Wound Care: Pattern of Follow-Up Visits and Evaluation}

- Double pad, antibiotic ointment to wound and in the eye (check first for allergies).

- Remove pad at home after $48 \mathrm{~h}$ and apply antibiotic ointment three times a day to wound.

- Follow-up in 1 week.

- Usually 2-3 weeks later the pedicles are divided and the flap insetting completed [18].

\section{Sliding Upper Eyelid Tarsoconjunctival Flap}

Indication for Surgery. In our opinion a bucket handle flap or an upper eyelid tarsoconjunctival flap (Hughes to the upper eyelid) is always preferable to a Cutler-Beard procedure as it is a singlestage procedure with a much better aesthetic result and avoids complications of the CutlerBeard such as entropion, lower eyelid retraction, and scarring [19, 20]. The upper eyelid sliding tarsoconjunctival flap is possible when some tarsus is preserved after Mohs excision. The residual tarsal plate slides, still attached to the upper conjunctival flap, is displaced inferiorly to repair the posterior lamella and is subsequently covered with a skin graft.

Potential complications of an upper eyelid sliding tarsoconjunctival flap include eyelid retraction, eyelid margin abnormality, lack of cilia, and abnormal eyelid contour. In comparison, direct (primary) closure avoids disrupting the eyelid margin contour and eyelash loss, but it often leads to residual upper eyelid ptosis.

\section{Standard Surgical Technique}

- A tarsoconjunctival flap is formed similarly to what happens for the lower eyelid from the upper half of the tarsal plate adjacent to the defect; vertical cuts are made continued superiorly into the conjunctiva toward the fornix to completely release the tarsoconjunctival flap.

- The extent of the incisions into the conjunctiva depends on the extent of flap mobilization required to close the defect under minimal/ modest tension.

- The conjunctiva is then released from the levator aponeurosis and Muller's muscle [20].

- The flap is then moved to fill the posterior lamellar defect and stored medially and laterally to the tarsal remnants.

- The tarsoconjunctival flap should be overcorrected inferiorly by about $1 \mathrm{~mm}$ beyond the anticipated new eyelid margin to allow for shrinkage.

- A FTSG or an upper eyelid skin-muscle advancement flap is used to repair the anterior lamella.

- The new anterior lamella is sutured to tarsus along the eyelid margin using 7-0 Vicryl sutures, taking care to avoid corneal irritation with the suture knots.

\section{Lower Lid Full Thickness}

Knowledge of different reconstructive options allows for planning of the surgical repair. Lower eyelid defects can be categorized by:

1. Amount of full-thickness eyelid defect (as percent of eyelid margin)

2. Degree of nonmarginal eyelid involvement

3. Total size of defect

4. Canthal involvement

5. Lacrimal involvement

Depending on the laxity of the eyelid tissues, full-thickness defects of the eyelid margin involving up to one-third of the horizontal length may be closed with direct closure (Table 4.2). Minimal tension can be released with a lateral canthotomy or cantholysis [1]. Larger defects may require use of the Tenzel or Hughes flaps.

Options for anterior lamellar reconstruction include skin grafts and local skin flaps. Skin graft sites include upper eyelids, postauricular, preauricular, supraclavicular, neck, or inner 
Table 4.2 Treatment of full-thickness lower eyelid defect

\begin{tabular}{l|l|l}
\hline Full-thickness defect size & Primary techniques & Adjunct techniques \\
\hline Small $(20-30 \%)$ & $\begin{array}{l}\text { Direct closure } \\
\text { Canthotomy with closure } \\
\text { Lateral advancement flap }\end{array}$ & - \\
\hline Medium (30-40\%) & Lateral advancement flap & $\begin{array}{l}\text { Canthal fixation } \\
\text { Canalicular reconstruction } \\
\text { Periosteal flap }\end{array}$ \\
\hline Large (>40-50\%) & $\begin{array}{l}\text { Lateral advancement flap } \\
\text { Hughes tarsoconjunctival flap } \\
\text { Mustarde cheek flap }\end{array}$ & $\begin{array}{l}\text { FTSG } \\
\text { Autogenous tarsal graft or hard palate mucosal graft } \\
\text { Medial canthotomy/cantholysis }\end{array}$ \\
\hline
\end{tabular}

arm. One should consider the type and distribution of hair in the donor graft [21]. Skin flaps include advancement, rotation, and transposition flaps. Flaps may have a base, direct pedicle, tubed or pedicle or be an island flap. Specific local eyelid flaps include O-to-T, V-to-Y, and rhombic flaps.

Periorbital flaps include transposition and rotation cheek flaps (Tenzel, Mustarde, etc.), glabellar flaps, paramedian forehead flaps, and temporal forehead flaps (Fricke). Flaps may need to be divided or inset as a second stage procedure several weeks after the initial repair, e.g., Hughes procedure [21].

Options for posterior lamellar reconstruction also include grafts or flaps [22, 23]. Flaps include tarsoconjunctival flap and can be central such as in a Hughes flap or lateral-based; in either case there is a pedicle of conjunctiva that provides vascular supply to the flap. Grafts may include tarsoconjunctival grafts, tarsomarginal grafts, hard palate grafts, and auricular cartilage grafts.

\section{Direct Closure: Wedge Excision}

Indication for Surgery. An eyelid defect of 25\% or less may be closed directly, and some authors have reported excellent results for defects much larger than this, closing the defect under considerable tension [4-6]. In patients with marked eyelid laxity or through the use of lateral canthotomy with or without cantholysis, a defect even larger than $50 \%$ of the eyelid may sometimes be able to be closed directly.

\section{Standard Surgical Technique}

- Initial wedge excision of the lesion with margin control

- Primary closure entails first repair of the tarsus with $2 \times$ buried 6-0 or 5-0 Vicryl sutures

- Then a 6-0 Vicryl lash line suture

- Sometimes a gray line suture (7-0 Vicryl, cut knot short to avoid corneal irritation)

- Finally repair of the anterior lamella with interrupted or continuous 6-0 Vicryl sutures $[16,23]$

\section{Cantholysis: Adjunct Procedure}

Indication for Surgery. The size of the defect that can be repaired in the lower eyelid can be increased if necessary by the addition of a lateral cantholysis. In elderly patients, eyelid defects of up to half the horizontal length of the eyelid or $14 \mathrm{~mm}$ can be directly repaired. This is sometimes a useful adjunct to direct closure.

\section{Standard Surgical Technique}

- Canthotomy is made with a size 15 blade or Westcott scissors.

- The lower limb of the lateral canthal tendon is released.

- The eyelid is slit at the gray line for at least $6 \mathrm{~mm}$.

- The lower canthal tendon fibers are released, but the upper lid tendon fibers must remain intact to avoid distortion of the canthus postoperatively.

- A traction (Frost) suture to elevate the lower lid for 48-72 h is sometimes useful (Fig. 4.8). 

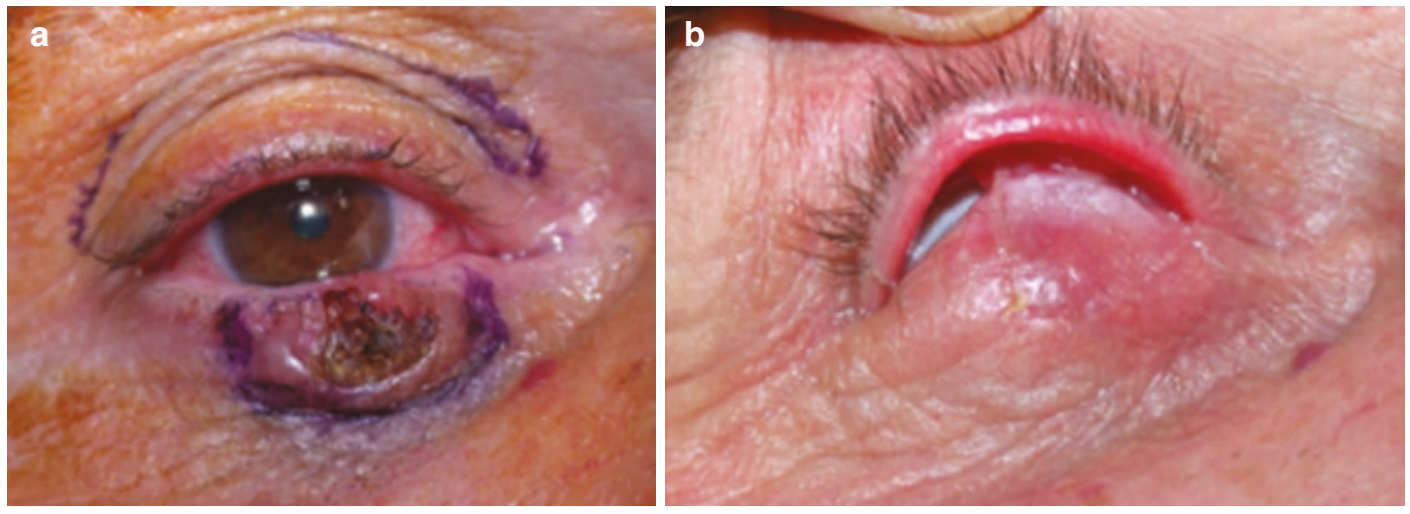

Fig. 4.8 (a, b) Inferior cantholysis adjunct to direct closure

\section{Tenzel Semicircular Flap}

See upper eyelid description.

Indication for Surgery. The main indication for a Tenzel flap is a larger full-thickness lower eyelid defect with up to half of the eyelid length involved; however, it may be used for defects up to $70 \%$ if the lower eyelid retractors and inferior orbital septum are identified and severed from their attachments [12].

\section{Hughes Tarsoconjunctival Flap}

Indication for Surgery. The original Hughes procedure was reported in $1937^{25}$ since which time some modifications have been made [25-29]. A modified Hughes tarsoconjunctival flap can be used for full-thickness defects of more than half the lower eyelid length $[16,25]$. This procedure can be used for defects involving the entire horizontal length of the lower eyelid. The integrity of the upper eyelid margin is retained by leaving the lower $4 \mathrm{~mm}$ of the upper tarsal plate intact [23].

One-eyed (monocular) patients and children in the amblyogenic age, whose vision may be affected by the temporary eyelid closure, are better served with single stage advancement flaps.

\section{Standard Surgical Technique}

- The defect should be assessed under gentle tension.

- A silk traction suture is passed through the gray line of the upper eyelid, which is everted over a Desmarres retractor [16].
- The tarsal conjunctiva incision line is marked with a surgical marking pen $4 \mathrm{~mm}$ above the eyelid margin.

- A superficial horizontal incision is made along the conjunctiva and tarsus $4 \mathrm{~mm}$ above the eyelid margin using a number 15 Bard Parker blade [16].

- The incision is deepened through the full thickness of the tarsus using the number 15 blade, and the horizontal incision is completed with Westcott scissors. Vertical relieving cuts are then made at both ends of the tarsal incision [16].

- Tarsus and conjunctiva are dissected free from Müller's muscle and the levator aponeurosis up to the superior fornix. The tarsoconjunctival flap is advanced into the lower eyelid defect to reconstruct the posterior lamella of the lower eyelid.

- The flap tarsus is sutured to the remaining lower eyelid tarsus edge with interrupted 6-0 Vicryl sutures. The lower eyelid conjunctival edge is sutured to the inferior border of the mobilized tarsus with a continuous or interrupted 6-0 Vicryl suture.

- A FTSG (preferred by us because it reduces the risks of cicatricial ectropion) or advancing a myocutaneous flap from the cheek can be used to reconstruct the anterior lamella. The graft or flap is sutured into place with 6-0 Vicryl sutures. 
- The skin edge is sewn to the superior aspect of the tarsus using interrupted 7-0 Vicryl sutures.

- The occasional use of oblique medial and lateral periosteal flaps in conjunction with the Hughes flap enables the repair of maximal defects of the lower eyelid [28]. Video 4.2Reconstruction with Hughes flap.

\section{Postoperative Medications and Wound Care: Pattern of Follow-Up Visits and Evaluation}

- Remove pad at home after $48 \mathrm{~h}$, and apply antibiotic ointment three times a day to wound.

- At a second operation, the conjunctival pedicle is cut and the lower eyelid margin reconstructed.

- Although the second operation has typically been performed 3-4 weeks after the first operation [25], the tarsoconjunctival pedicle may be safely divided at 2 weeks [29] and even as early as 7 days [29].

\section{Second Stage}

- Local anesthesia with propofol sedation.

- 27G-30G needle, $1 \%$ ropivacaine with 1:100,000 adrenaline, injected into the upper and lower eyelids.

- Next, one blade of a pair of Westcott scissors is inserted just above the desired level of the new eyelid border, and the flap is cut open ${ }^{16}$ (Fig. 4.9).

- The upper eyelid is then everted, and the residual flap is excised using Westcott scissors.

- The anterior and posterior lamellar margin are sutured together with 7-0 Vicryl sutures.

\section{Single-Stage Advancement Flaps} +/- Free Grafts

Indications for Surgery. Disadvantages of the Hughes flap are not insignificant and include [30]:

1. The eye is closed postoperatively for 1-2 weeks or longer.

2. A second stage is required.

3. There is a loss of eyelashes in the area of the flap.

4. The edge of the flap can be persistently erythematous.

These disadvantages have prompted the search for alternative single-stage procedures. Reconstruction of the anterior lamella in fullthickness eyelid defects can be accomplished by a number of different techniques, each with some variations. FTSGs may be utilized if the tarsal flap has a vascular supply (Hughes flap) or when an orbicularis muscle flap is advanced. A myocutaneous pedicle flap will typically result in a better color and thickness match [31]. Free tarsoconjunctival (TC) flaps associated with myocutaneous advancement flaps are less likely to lead to complications of eyelid margin erythema and subsequent revision surgery than Hughes TC flaps with FTSGs [32]. They are also single stage procedures and thus useful for monocular patients.

Other single-stage alternative procedures to the Hughes flap for reconstruction of large lower eyelid defects have recently gained favor and include lateral-based full-thickness advancement flaps [33] and
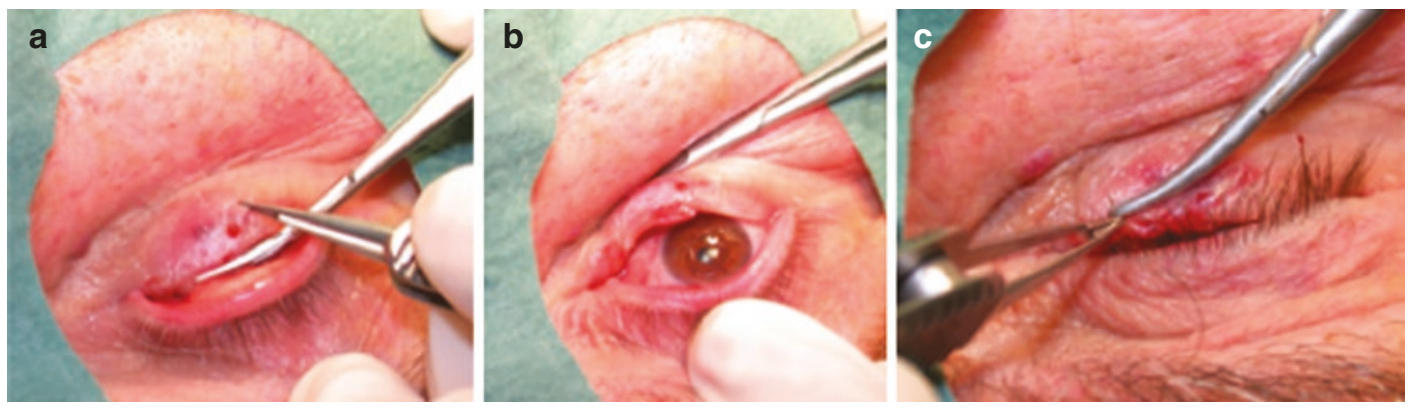

Fig. 4.9 (a-c) Stage 2 of the Hughes procedure 
free tarsoconjunctival graft and myocutaneous transposition flap [34]. Perry and Allen described successful single-stage reconstruction of large full-thickness defects of the lower eyelid which involve 50-75\% of the horizontal length of the eyelid [30]. The procedure employs lateral stabilization of the posterior lamella with a periosteal strip, medial transposition of the lateral posterior lamella for central and medial defects, and a myocutaneous advancement flap to stabilize the anterior lamella. For defects $\geq 66 \%$ of the lower eyelid, a free tarsal graft is often necessary in addition to the periosteal strip to complete posterior lamellar reconstruction [30].

\section{Standard Surgical Technique: Lateral- Based Full-Thickness Advancement Flap}

\section{Indication}

Full-thickness lower eyelid defect greater than $50 \%$ eyelid width with no tarsus remaining; minimum 25\% full-thickness lateral lower eyelid intact for medial advancement [33] (Fig 4.10a).

\section{Technique}

- The horizontal dimension of the lower eyelid defect is measured along with the residual lateral full-thickness lower eyelid. Lateral incisional markings are then drawn [33] (Fig 4.10b).

- A full-thickness advancement flap, based laterally, is created. The skin height in the flap is made 1-2 mm greater than the skin height in the defect [33] (Fig 4.10c).

- The conjunctiva and retractor-orbital septum fused complex are incised along the inferior border of the tarsal plate and then incised vertically, $1 \mathrm{~mm}$ or so anterior to the lateral fornix recess, cutting down onto the periosteum of the lateral orbital rim [33].

- The lateral palpebral raphe tissue at that point is lysed, until the posterior lamella is
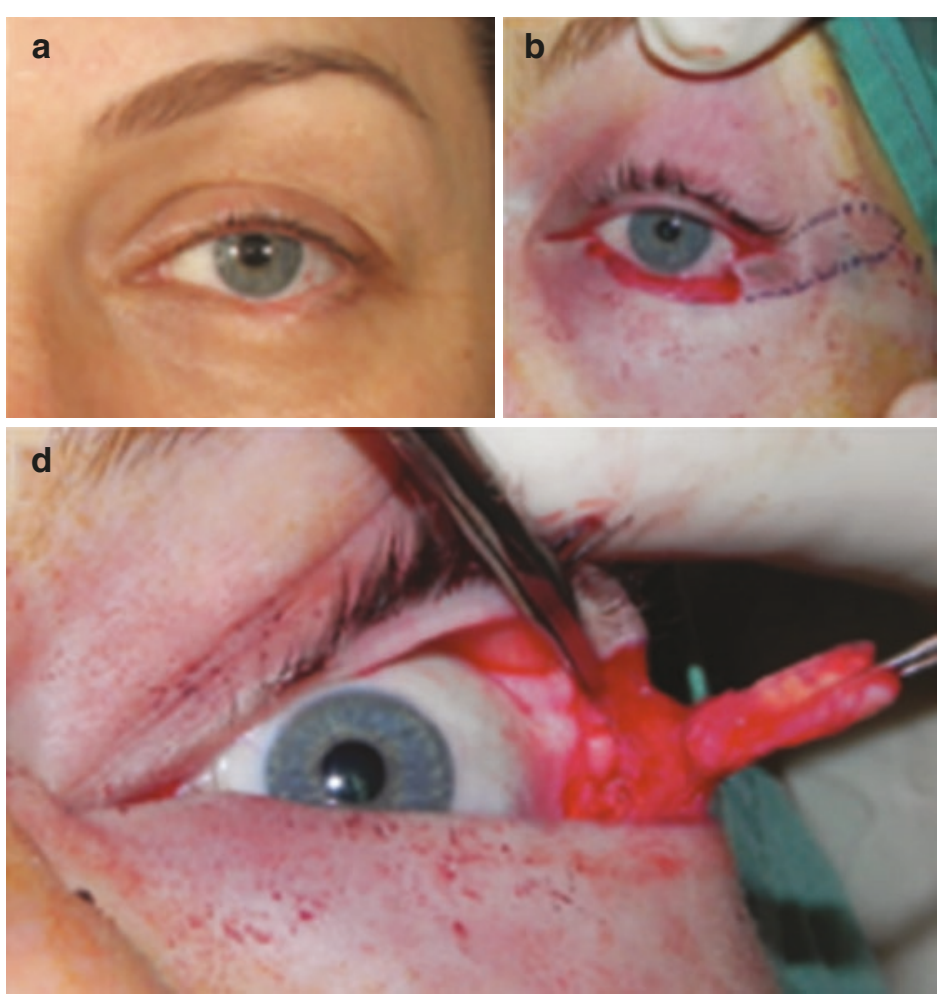
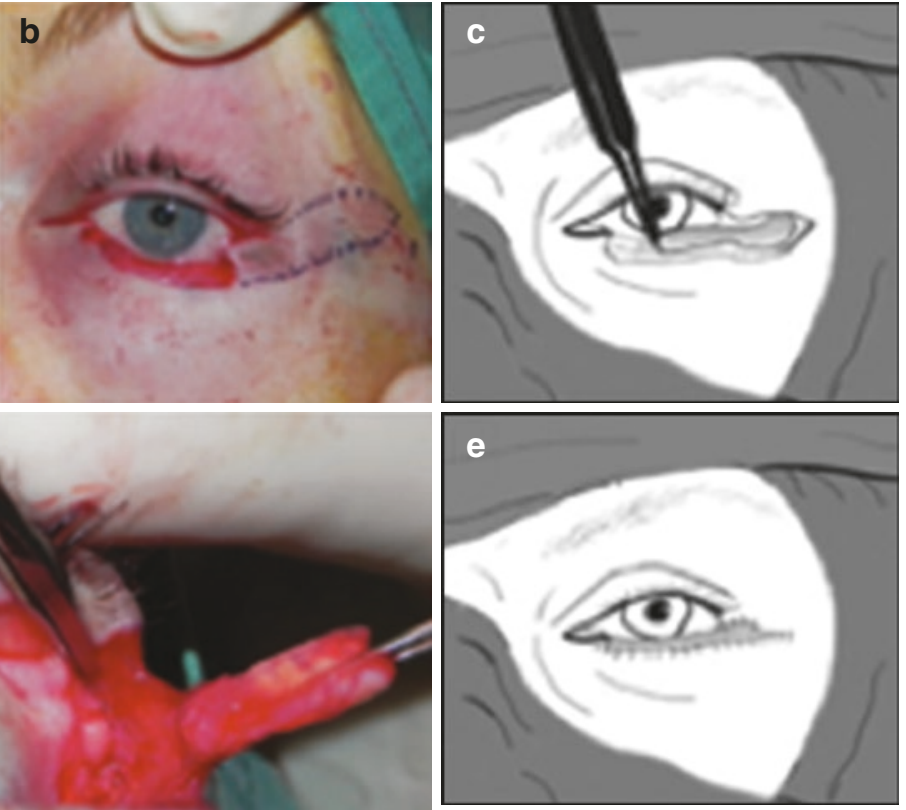

Fig. 4.10 (a-g) Single staged flap. (From Skippen et al. [33], with permission) 

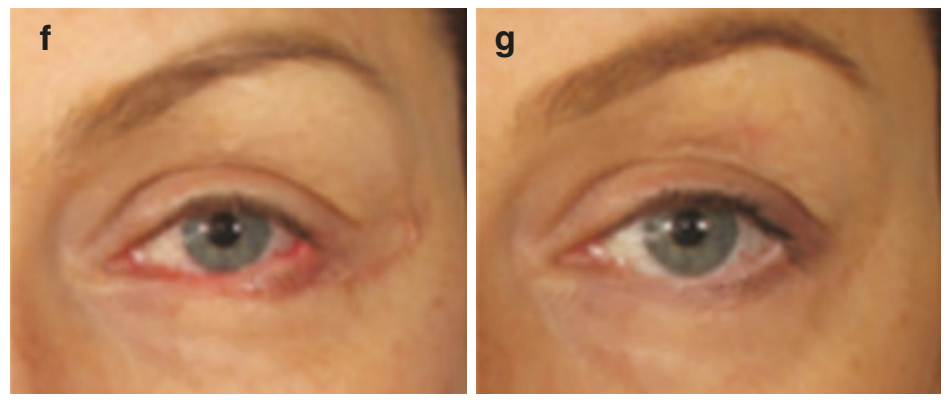

Fig. 4.10 (continued)

completely mobilized from the orbital rim (Fig 4.10d).

- From the lateral eyelid wound edge, the skin is incised laterally, superiorly, and inferiorly in parallel with the curve of the eyelid margin. The full-thickness eyelid flap is then advanced medially to ascertain whether there needs to be further mobilization of the lateral skin base in a V-Y manner [33].

- The medial tarsal edge of the full-thickness flap is sutured to the medial edge of the defect with two 6-0 Vicryl interrupted sutures. A continuous 6-0 Vicryl suture is run along the inferior conjunctival margin of the flap with the knots buried away from the ocular surface [33].

- The anterior lamella of the flap is sutured to the skin edge of the defect with 6-0 Vicryl sutures (Fig 4.10e).

Another means of laterally located large, full-thickness repair of large lower eyelid defects consists of the creation of a lateral-based tarso-conjunctival flap with vascular supply coming from the lateral conjunctiva; the tarsoconjunctival flap is severed from the donor eyelid as if it was a free tarsal graft, except for the lateral most part attached to the conjunctiva; the flap can be fully mobilized to reach the recipient bed in the lower eyelid and anchored into the new position; subsequently a FTSG or better a skin/muscle flap from the same upper eyelid (Fig. 4.11), providing the best functional and cosmetic result.

Mustarde's Cheek Rotation Flap. A large lower eyelid defect, also involving the cheek, can classically be reconstructed with Mustarde's cheek rotation flap, which utilize the lateral cheek and zygomatic skin to cover a posterior lamellar graft $[16,23]$. Excision of a significant amount of normal tissue is required in the cheek area to avoid a dog ear deformity and this flap is reserved for large lower eyelid defects extending to the cheek, rather than isolated lower eyelid defects. The flap size needs to be 3-4 times the area of the primary defect. It is important to remember that this is a rotation flap rather than a simple advancement and thus requires a very significant degree of undermining.

\section{Medial Canthus Reconstruction}

Reconstruction of the medial canthus after the excision of cutaneous malignancy is challenging not only from an aesthetic aspect, but also due to the complexity of the medial canthal anatomy and its importance for vision and eyelid function. Furthermore, there is minimal laxity of skin in this region, often precluding primary closure of defects. In addition to consideration of eyelid and medial canthal skin reconstruction, the nasolacrimal apparatus requires attention to avoid or treat potentially disabling epiphora [35]. Primary closure is sometimes possible, depending on the excision technique used, i.e., Moh's, frozen section, and delayed paraffin.

For larger anterior defects, or those lacking a vascular bed for FTSG survival, various transposition or advancement flaps can be employed, such as a glabellar forehead flap or paramedian 

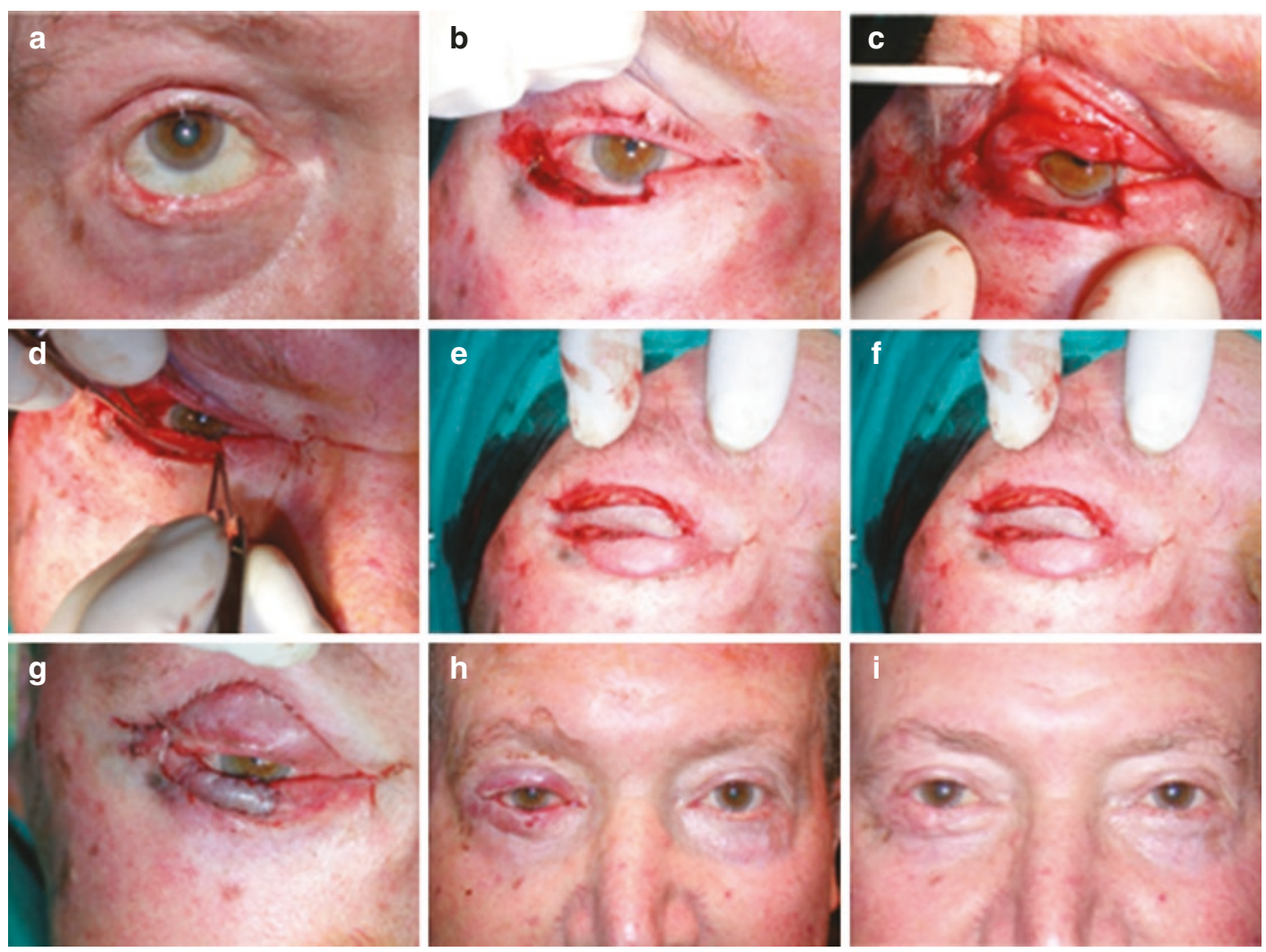

Fig. 4.11 (a-i) Large lower eyelid defect repair using lateral-based tarso-conjunctival flap

forehead flap $[2,36]$. When the defect involves full-thickness medial eyelid(s) or sacrifice of the medial canthal tendon, the remaining eyelid must be reapproximated and fixated to periosteum or bone [38]. When the medial canthal tendon is interrupted or completely lost, the remaining eyelid portion of the tendon must be fixated to the area of the tendinous origin to ensure proper alignment and support of the eyelid(s). If only the anterior limb of the tendon is disrupted, it may not cause malposition of the medial canthus if the posterior limb remains intact [24]. If any tendon remains on the anterior or posterior lacrimal crest, direct reattachment with polygalactin (Vicryl) or polypropylene (Prolene) suture is possible.

\section{Reconstruction Options}

1. Laissez-faire (small, shallow defects)

2. Direct closure
3. Glabellar or bilobed flaps (if poor vascular support; need to be thinned)

4. Paramedian forehead flap [37]

5. Combination flaps for deeper defects [36]

6. FTSG (if good vascular support; larger defects)

Some of the problems encountered in reconstruction in this area include [35]:

1. A difference in skin color between host tissue and skin grafts used for reconstruction

2. Differing skin textures, for example, thick skin from the glabellar region is often a poor match for medial canthal skin

3. Poor eyelid motility and function, which requires adequate canthal tendon fixation in the appropriate position and at the correct tension

4. Loss of volume in the concavity of the medial canthus, which tends to be cosmetically obvious 
5. Limited globe motility, typically reduced abduction, which may result from a conjunctival cicatrix

6. Chronic epiphora, which may result from secondary corneal exposure, an abnormal lid position or damage to the nasolacrimal system

\section{Laissez-Faire (Spontaneous Granulation)}

After its initial description by Fox and Beard in 1964, the laissez-faire method has become wellestablished as a method of medial canthal reconstruction, with excellent cosmetic results [42]. Excess scar formation may occasionally occur, which may lead to difficulties in subsequent tumor surveillance, but this may be dealt with surgically using standard techniques. Scarring may be reduced in defects that symmetrically bisect the medial canthal tendon with appropriate contouring and alignment along the relaxed skin tension lines (RSTL) [35].

\section{Direct Closure of the Defect}

Where possible, direct closure of the edges of a defect typically provides excellent cosmetic results, however, the use of this technique has traditionally only been used for small defects due to concern about closing defects under tension and subsequent unacceptable distortion of the palpebral apertures. However, it has recently been shown that even when eyelid defects are closed under extreme tension, intraoperative, and postoperative tissue expansion allows the dimensions of the palpebral apertures to return to normal after a period of a few months [15].

\section{Mobilization of Nasal Skin into a Medial Canthal Defect}

Indication for Surgery. A variety of techniques involving flaps have been described, permitting mobilization of infraglabellar nasal skin into a medial canthal defect, all of which allow defect closure within a single aesthetic facial unit [35].

\section{The Rhomboid Transposition Flap}

This provides a simple and versatile method for medial canthal reconstruction [38]. Custer also described a transnasal flap, similar in construction to a rhomboid flap but triangular in shape, which has been reported to provide excellent cosmetic results in 22 patients [39].

Advantages of using a rhomboid flap include:

- Scar length minimized

- Tissue excision minimized

- Easier to work with straight defect sides

\section{Standard Surgical Technique}

- The defect, which may be an irregular shape, is conceptualized as a rhomboid shape, with its long-axis perpendicular to the relaxed skin tension lines (RSTL).

- Short diagonal of excised rhomboid on the same line with RSTL.

- A flap adjacent to typically the upper half of the defect (greater skin motility superiorly) is mobilized, which is then transposed into the defect.

- Base of triangle of donor flap perpendicular to RSTL.

- After flap advancement, the greatest tension lies in closing the triangular donor site.

- Undermining of tissues allows closure of the secondary defect.

- Tissue closure with interrupted 6-0 Vicryl sutures.

\section{The Bilobed Flap}

This is an alternative versatile option to the rhomboid flap and uses two lobes of skin on a shared pedicle and is thus a double transposition flap [40]. This technique permits movement of more skin over longer distance than possible with single transposition flap.

\section{Standard Surgical Technique}

- Each lobe of the defect is tethered to a cutaneous pedicle.

- The proximal lobe is transposed into the defect, whereas the second lobe is rotated into the defect created by the first.

- The first lobe is designed to be equal to the width of the original defect. 
- The defect arising from the second pedicle can usually be closed directly, in a linear fashion.

- This defect bears the greatest closure tension and is best placed in a natural skin crease where possible.

- Tissue closure with interrupted 6-0 Vicryl sutures.

\section{Mobilization of Forehead or Glabellar Tissue}

Mobilization of tissue as a flap from the forehead or glabellar area can be achieved through a bilobed flap [40] as described above, or a glabellar flap as described by McCord and Wesley [41]. The underlying rich vascular supply of this region allows for a very robust flap. Such forehead flaps can preserve their vascular pedicle along an axial pattern, such as a paramedian forehead flap.

\section{Mobilization of Upper Eyelid Anterior Lamella}

Skin and/or orbicularis may be mobilized from the upper eyelid using a variety of flap techniques [42]. Dermatochalasis may provide a large amount of redundant skin that can be mobilized with little local morbidity in a cosmetically acceptable manner. Tissue flaps can be advanced through a rotation flap, hinged laterally, or more commonly through a medially based pedicle, which allows the movement of larger quantities of skin and or muscle; this latter technique, when used bilaterally, can also be used in the reconstruction of the entire superficial upper half of the nose. Thin eyelid skin, however, does not always allow adequate volume replacement of the medial canthal hollow [35].

\section{Mobilization of Cheek, Forehead, and Midface Tissue}

Upward movement of nasolabial, cheek, and midfacial tissue into a medial canthal defect can be achieved through rotation and/or transposition flaps, but is perhaps more simply achieved with a subcutaneous island pedicle advancement flap [43]. The design of the flap is "V-Y," with the lower part of the defect being closed to form the limb of the "Y." Such flaps provide wellvascularized tissue and are easily combined with other techniques, such as a forehead or glabellar flap, for larger defects. Disadvantages include a downward vector of the flap, which may predispose to subsequent medial ectropion [35].

\section{Paramedian Forehead Flap}

Indication for Surgery. For large medial canthal defects, a paramedian forehead flap can be useful [37]. The paramedian forehead flap method elevates the flap with the supratrochlear vessels and nerves, ensuring an abundant blood supply. The common paramedian forehead flap utilizes the contralateral supratrochlear artery as the pedicle and has the merit of not bending the artery severely due to its large rotation arc. A paramedian forehead flap method utilizing the ipsilateral supratrochlear artery has also been described, with good results [37].

Disadvantages of the paramedian forehead flap include the procedure needing two stages and the relatively poor aesthetic outcome compared to other techniques. The pedicle crossing the skin of the nose like a tube requires second stage flap division, usually after 2-3 weeks [37].

\section{Combination Flaps}

Indication for Surgery. For larger, deeper medial canthal defects [36].

\section{Standard Surgical Technique}

- Lacrimal system intubated with Crawford tubes during tumor excision

- Medial canthal angle recreated first with 4-0 Vicryl onto periosteum of posterior lacrimal crest then medial part of the eyelid defect

- Glabellar rotational flap used for superomedial part of the defect

- Lateral-based upper eyelid advancement flap used for lateral part of defect

- Posterior parts of both flaps fixated to periosteum in medial canthus with 5-0 Vicryl sutures

- Skin incisions closed with 6-0 Prolene and 5-0 fast absorbing gut sutures (Fig. 4.12) 

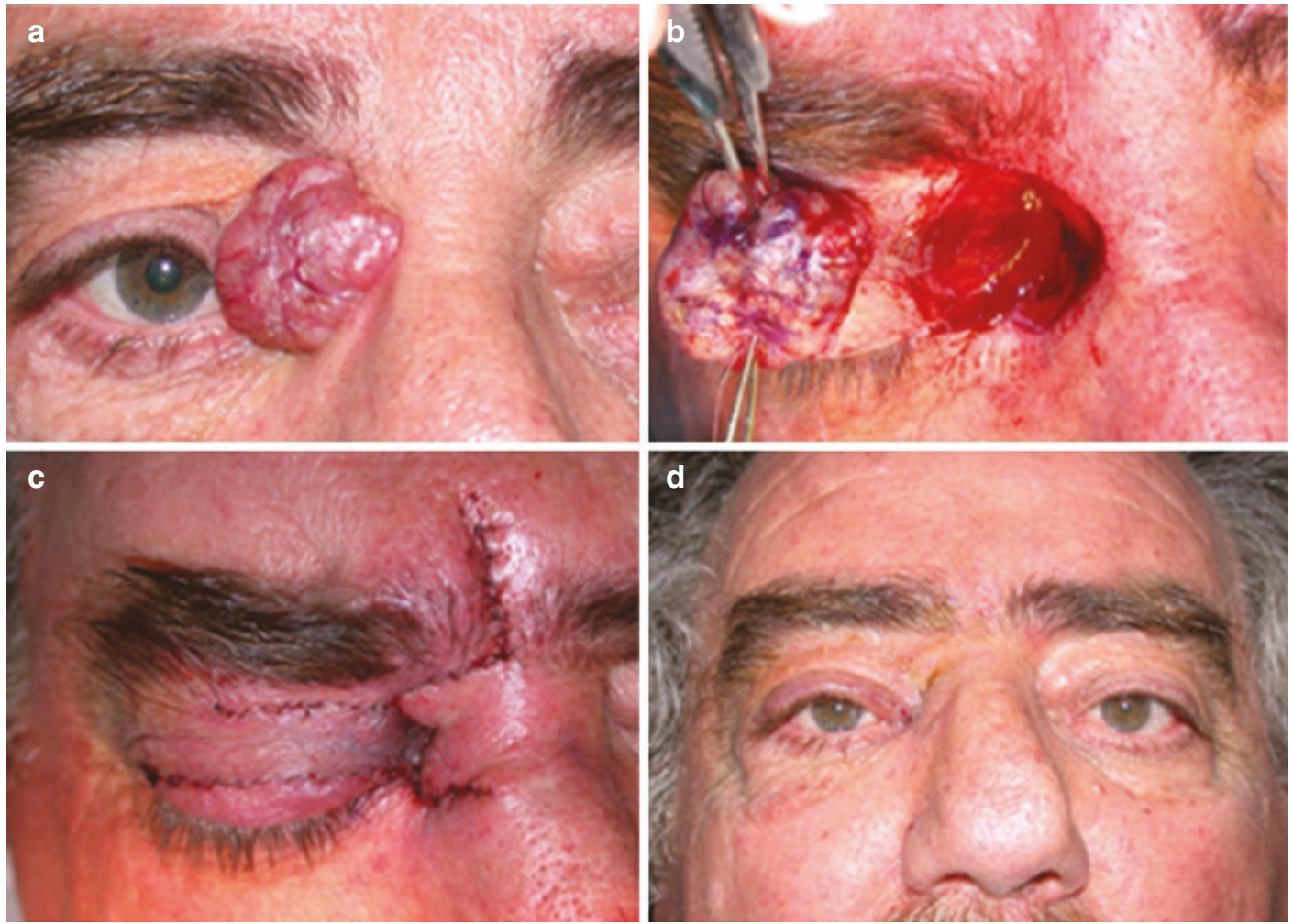

Fig. 4.12 (a-d) Combination flaps for large, deep right medial canthal defect

\section{Skin Grafting}

Indication for Surgery. Medial canthal defects can also be effectively covered by means of skin grafting, which can be either a split-thickness graft (SSG) or more typically a FTSG [44]. Contracture of skin grafts seems to occur more frequently as the thickness of the graft decreases, which often precludes the use of SSG in this region. FTSGs for the medial canthal region are typically harvested from the upper eyelid skin, preauricular or postauricular areas, inner brachial, and supraclavicular areas [44].

\section{Lateral Canthus Reconstruction}

Reconstruction of the lateral canthus, or canthoplasty, is not as well described as that of the medial canthus. Reconstruction of the lateral canthus is dependent upon the extent of injury to the surrounding tissues. The key to adequate reconstruction is correct recognition of the extent of injury and the correct fabrication of the damaged or missing structures [45]. Options for skinonly defects differ from options for full-thickness defects. The lateral canthal angle needs to be reformed. If eyelid laxity is present, then options include lateral canthopexy and a lateral tarsal strip. Other considerations in this region include skin rotation flaps for anterior lamella and periosteal flaps for posterior lamella.

Commonly used surgical procedures in this region include (done after complete clearance of the tumor, with adequate margins):

\section{- Primary closure}

- Advancement flap, rhomboid flap, rotation flap, transposition flap

- Combination flaps

- Lateral periosteal flaps can be helpful if lateral upper lid or lower lid tarsal loss

- FTSG 


\section{Skin-Only Defects}

\section{Primary Closure}

For small lesions, primary closure is the best method of reconstruction. Closing the defect in the direction of relaxed skin tension lines is typically the best orientation to perform primary closure. However, in the area of the lateral canthus, facial rhytids are described to occur in a crow's feet distribution. These rhytids do not always follow the relaxed skin tension lines and care should be taken to orient the scars with regards to the crow's feet orientation [45].

\section{Rhomboid Flap}

Indication for Surgery. Initially described by Limberg, the rhomboid flap is useful for skin reconstruction at the lateral canthus [46]. Advantages of the flap are its ability to minimally distort important adjacent anatomic structures while providing a similar skin for the defect reconstruction.

\section{Standard Surgical Technique}

- Excise the defect as a rhomboid so that its $120^{\circ}$ angle is located at the area of greatest skin excess.

- A line is then drawn out into this skin excess from the apex of the $120^{\circ}$ angle equal to the length of one side of the rhomboid.

- A $60^{\circ}$ cut is then drawn at the end of this line.

- This line will be parallel and equal in length to the side of the rhomboid defect.

- The flap is then cut and transposed so that the apex of the $60^{\circ}$ cut is inserted in the $60^{\circ}$ angle of the rhomboid defect.

- Undermining of tissues allows closure of the secondary defect.

- Tissue closure with interrupted 6-0 Vicryl sutures.

\section{Fricke Flap}

The Fricke flap is an inferiorly based transposition flap designed in the forehead or temporal skin area and rotated medially to cover skin defects at the lateral canthus [47]. It can also be used for large lower eyelid full-thickness defects.
When the flap is narrow the donor site can be closed primarily but care should be taken not to move the eyebrow laterally or the hairline anteriorly. Larger flaps may require FTSG closure of the donor site, which may leave an aesthetically unsatisfactory result.

An alternative for primary donor site closure is the use of a bipedicle flap instead of the Fricke flap transposition. Other forehead flaps with/ without preservation of the vascular pedicle (i.e., paramedian forehead, axial pattern flaps, etc.) may be useful [45].

\section{Lateral Canthal Tendon Repair}

Reestablishment of the attachment of the lateral canthal tendon to the internal aspect of the lateral orbit at Whitnall's tubercle is a surgical goal if the continuity of these two structures has been disrupted. The vector that has been described for representing the lateral canthus is one of a superior and lateral direction with periosteal fixation [48]. If both upper and lower eyelid structures are involved laterally, periosteum from both the upper and lower lateral orbital rim may be required to reconstitute the lateral canthal structure [49].

\section{Full-Thickness Defects}

Full-thickness loss at the lateral canthus almost always involves loss of adjacent structures such as the eyelids. Reconstruction of these fullthickness defects requires both the reconstruction of the lateral canthus and that of the adjacent eyelids and tarsal plates [50]. Replacement materials for these reconstructive cases may include autogenous tarsal flaps or grafts, hard palate mucosa, palmaris longus tendon, temporal parietal fascia, nasal mucosal tissues, dermal fascia, ear cartilage, cadaver sclera, and various animal, cadaver or artificial skin, dermis or fascial implants [51, 52]. Therefore, a combination of the techniques described above may be needed to reconstruct full-thickness lateral canthal defects (Fig. 4.13). 

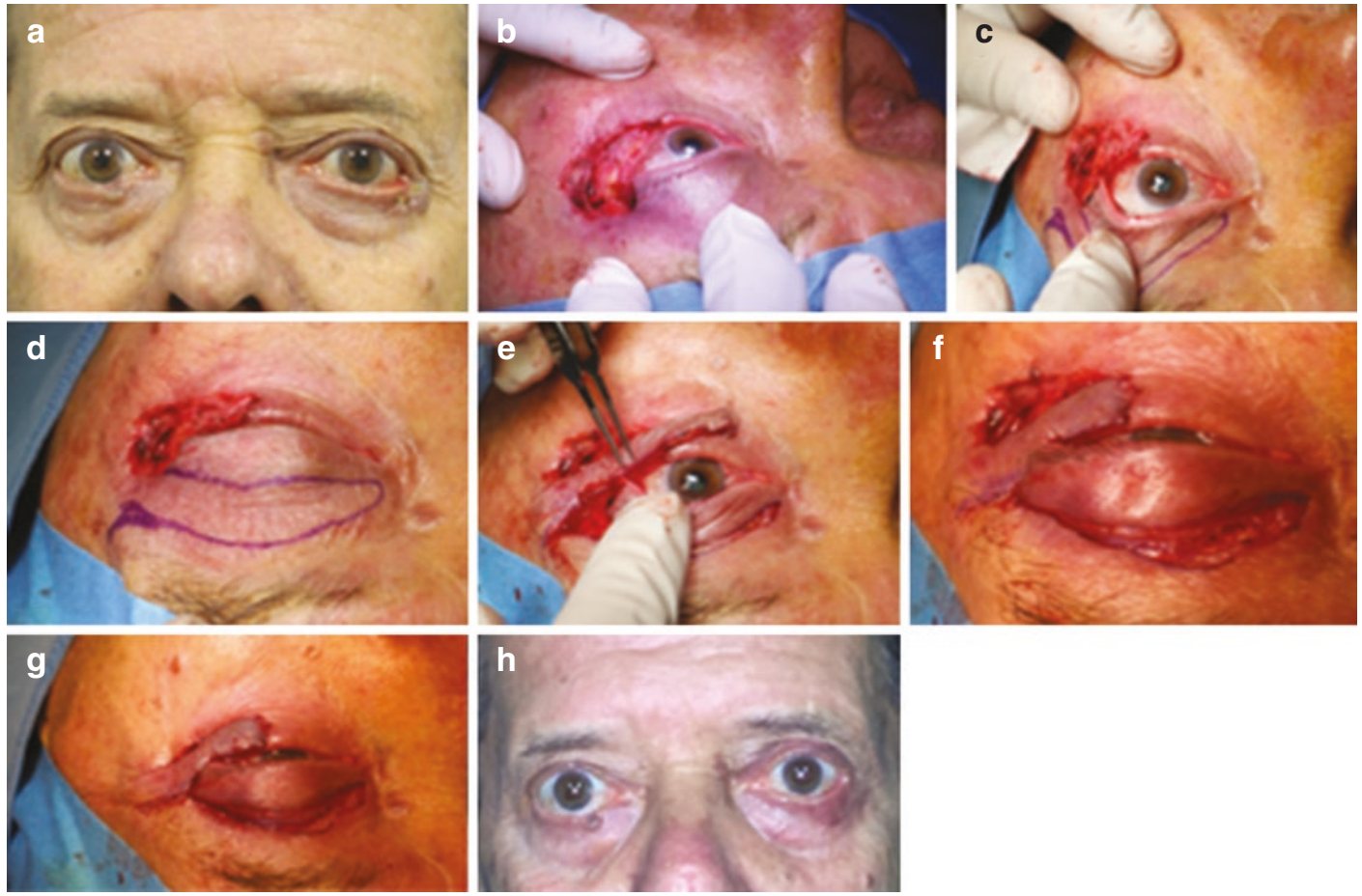

Fig. 4.13 (a-h) Lateral canthal defect repairing lateral-based upper-eyelid transposition flap

\section{Postoperative Medications and Wound Care: Pattern of Follow-Up Visits and Evaluation}

In general terms, for most eyelid procedures where a skin graft is not used, the postoperative management is similar.

- Management may be more complicated for dark skin patients due to the increased risk of hypertophic scars:

- Antibiotic ointment to wound and in the eye (check first for allergies), double pad, tape.

- Remove pad at home the next day and apply antibiotic ointment three times daily to wound.

- When skin grafts are used, the pad should be left intact for a minimum of $48 \mathrm{~h}$.

- Follow-up in 1 week.

\section{Complications of Eyelid Reconstruction}

\section{Upper Eyelid}

The main complications of upper eyelid repair involve either the eyelid margin or the position of the eyelid [3].

Eyelid margin problems include:

- Notching

- Trichiasis

- Conjunctivalization

Complications relating to the upper eyelid position includes:

- Entropion

- Retraction and exposure

- Ptosis 
Finally, unevenness of the posterior lamella such as after a posterior lamella or tarsal graft can result in reduced corneal lubrication and subsequent discomfort.

\section{Lower Eyelid}

Complications of lower eyelid repair can include [1]

Blurred vision or ocular irritation, secondary to:

- A suture

- Tissue irritation on the ocular surface

- Exposure keratopathy

Decreased orbicularis function with lagophthalmos

Swelling can cause mechanical ectropion

Excessive scarring can occur after reconstruction

Cicatricial ectropion

\section{Medial Canthus}

The predominant complications in this area include [35]:

- Cicatricial contracture, e.g., eyelid malposition

- Epiphora

- Web deformities

\section{Lateral Canthus}

Potential complications include [45]:

- Trichiasis

- Ocular surface irritation

- Ectropion

- Entropion

\section{Full-Thickness Skin Graft Complications}

The periocular region is a favorable FTSG recipient area by virtue of its high vascularity [53]. The usual donor sites for harvesting FTSG for the periocular area are upper eyelid, preauricular, postauricular, neck, clavicular, supraclavicular, and inner brachial area. Different sites yield different graft thickness.

\section{Complications}

Early complications seen in the first 2 weeks include [53]:

- Bleeding with hematoma formation beneath the graft

- Infection

- Seroma formation

These complications may prevent graft adherence to the underlying wound bed, prolong the ischemic phase, compromise the graft's vascular supply, and result in graft failure.

Late complications seen by 3 months are [53]:

- Cicatricial ectropion

- Graft hypertrophy and contracture

The long-term complications are mainly cosmetic or functional and result from color and texture mismatch, and hyper or hypopigmentation.

\section{References}

1. Holds JB. Lower eyelid reconstruction. Facial Plast Surg Clin N Am. 2016;24:183-91.

2. Czyz CN, Cahill KV, Foster JA, Michels KS, Clark $\mathrm{CM}$, Rich NE. Reconstructive options for the medial canthus and eyelids following tumor excision. Saudi J Ophthalmol. 2011 Jan;25(1):67-74.

3. O'Donnell BA, Mannor GE. Oculoplastic surgery for upper eyelid reconstruction after cutaneous carcinoma. Int Ophthalmol Clin. 2009. Fall;49(4):157-72. 
4. Fox SA, Beard C. Spontaneous lid repair. Am J Ophthalmol. 1964;58:947-52.

5. Mehta HK. Spontaneous reformation of lower eyelid. Br J Ophthalmol. 1981;65:202-8.

6. DaCosta J, Jones C. Laissez-Faire: how far can you go? Orbit. 2009;28:12-5.

7. Shankar J, Nair RG, Sullivan SC. Management of peri-ocular skin tumors by laissez-faire technique: analysis of functional and cosmetic results. Eye. 2002;16:50-3.

8. Colin JRO. Eye lid reconstruction \& tumor management. In: Colin JRO, editor. A Manual of Systematic Eye Lid Surgery. Edinburgh: Churchill Livingstone; 1989.

9. Thaller VT, Then KY, Luhishi E. Spontaneous eyelid expansion after full thickness eyelid resection and direct closure. Br J Ophthalmol. 2001 Dec;85(12):1450-4.

10. Johnson TM, Brown MD, Sullivan MJ, et al. Immediate intraoperative tissue expansion. J Am Acad Dermatol. 1990;22:283-7.

11. Espinoza GM, Prost AM. Upper eyelid reconstruction. Facial Plast Surg Clin North Am. 2016 May;24(2):173-82.

12. Tenzel RR. Reconstruction of the central one half of an eyelid. Arch Ophthalmol. 1975;93:125-6.

13. Cutler NL, Beard C. A method for partial repair and total upper lid reconstruction. Am J Ophthalmol. 1955;39:1-7.

14. Weinstein GS, Anderson RL, Tse DT, et al. The use of a periosteal strip for eyelid reconstruction. Arch Ophthalmol. 1985;103:357-9.

15. Thaller VT, Then KY, Luhishi E. Spontaneous eyelid expansion after full-thickness eyelid resection and direct closure. Br J Ophthalmol. 2001;85:1450-4.

16. Leatherbarrow B. Eyelid reconstruction. In: Leatherbarrow B, editor. Oculoplastic surgery. London: Martin Dunitz; 2002. p. 117-39.

17. Hsuan J, Selva D. Early division of a modified CutlerBeard flap with a free tarsal graft. Eye. 2004;18:714-7.

18. Dukic Y. Reconstruction of the upper eyelid with a pedicled bucket-handle brow flap. Face. 2009;6(3):165-7.

19. Jordan DR, Anderson RL, Nowinski TS. Tarsoconjunctival flap for upper eyelid reconstruction. Arch Ophthalmol. 1989;107:599-603.

20. Irvine F, McNab AA. A technique for reconstruction of upper lid marginal defects. Br J Ophthalmol. 2003;87:279-81.

21. Kakizaki H, Madge SN, Mannor G, Selva D, Malhotra R. Oculoplastic surgery for lower eyelid reconstruction after periocular cutaneous carcinoma. Int Ophthalmol Clin. 2009. Fall;49(4):143-55.

22. Mustarde JC. Repair and reconstruction in the orbital region. A practical guide. Edinburgh: Churchill Livingstone; 1980. p. 92-129.

23. Collin JRO. Eyelid reconstruction and tumor management. In: Collin JRO, editor. A Manual of Systemic Eyelid Surgery. 3rd ed. Philadelphia: Elsevier; 2006. p. 73-98.
24. Hughes WL. A new method for rebuilding a lower eyelid: report of a case. Arch Ophthalmol. 1937; 17:1008-17.

25. Hughes WL. Total lower lid reconstruction: technical details. Trans Am Ophthalmol Soc. 1976;74:321-9.

26. McNab AA. Early division of the conjunctival pedicle in modified Hughes repair of the lower eyelid. Ophthalmic Surg Lasers. 1996;27:422-4.

27. Maloof A, Ng S, Leatherbarrow B. The maximal Hughes procedure. Ophthal Plast Reconstr Surg. 2001;17:96-102.

28. McNab AA, Martin P, Benger R, O’Donnell B, Kourt G. A prospective randomized study comparing division of the pedicle of modified Hughes flaps at two or four weeks. Ophthal Plast Reconstr Surg. 2001 Sep;17(5):317-9.

29. Leibovitch I, Selva D. Modified Hughes flap. Ophthalmology. 2004;111:2164-7.

30. Perry CB, Allen RC. Repair of $50-75 \%$ fullthickness lower eyelid defects: lateral stabilization as a guiding principle. Indian J Ophthalmol. 2016 Aug;64(8):563-7.

31. Leone CR Jr, Van Gemert JV. Lower lid reconstruction using tarsoconjunctival grafts and bipedicle skinmuscle flap. Arch Ophthalmol. 1989;107:758-60.

32. Hawes MJ, Grove AS Jr, Hink EM. Comparison of free tarsoconjunctival grafts and Hughes tarsoconjunctival grafts for lower eyelid reconstruction. Ophthal Plast Reconstr Surg. 2011;27:219-23.

33. Skippen B, Hamilton A, Evans S, Benger R. Onestage alternatives to the Hughes procedure for reconstruction of large lower eyelid defects: surgical techniques and outcomes. Ophthal Plast Reconstr Surg. 2016;32:145-9.

34. Katz TL, Pennington TE, Yohendran J, et al. Onestep reconstruction of large lower eyelid defects: technique and outcomes. Clin Exp Ophthalmol. 2014;42:889-92.

35. Madge SN, Malhotra R, Thaller VT, Davis GJ, Kakizaki H, Mannor GE, Selva D. A systematic approach to the oculoplastic reconstruction of the eyelid medial canthal region after cancer excision. Int Ophthalmol Clin. 2009. Fall;49(4):173-94.

36. Chahal HS, Allen RC. Combination lateral rotational and glabellar flaps for medial canthal defects. JAMA Facial Plast Surg. 2016 Dec 1;18(6):491-2.

37. Kim JH, Kim JM, Park JW, Hwang JH, Kim KS, Lee SY. Reconstruction of the medial canthus using an ipsilateral paramedian forehead flap. Arch Plast Surg. 2013 Nov;40(6):742-7.

38. Ng S, Inkster CF, Leatherbarrow B. The rhomboid flap in medial canthal reconstruction. Br J Ophthalmol. 2001;85:556-9.

39. Custer PL. Trans-nasal flap for medial canthal reconstruction. Ophthalmic Surg. 1994;25:601-3.

40. Sullivan TJ, Bray LC. The bilobed flap in medial canthal reconstruction. Aust NZ J Ophthalmol. 1995;23:42-8.

41. McCord CD Jr, Wesley R. Reconstruction of the upper eyelid and medial canthus. In: McCord Jr CD, editor. 
Oculoplastic and Orbit Surgery. 2nd ed. New York: Raven Press; 1987.

42. Jelks GW, Glat PM, Jelks EB, et al. Medial canthal reconstruction using a medially based upper eyelid myocutaneous flap. Plast Reconstr Surg. 2002;110:1636-43.

43. Li JH, Xing X, Liu HY, et al. Subcutaneous island pedicle flap. Variations and versatility for facial reconstruction. Ann Plast Surg. 2006;57:255-9.

44. Leibovitch I, Huilgol SC, Hsuan JD. Incidence of host site complications in periocular full thickness skin grafts. Br J Ophthalmol. 2005;89:219-22.

45. Andrews BT, Lin SJ, Rubin PA. Lateral canthal reconstruction after head-neck or periocular cutaneous malignancy: oculoplastic and facial plastic surgery techniques. Int Ophthalmol Clin. 2009. Fall;49(4):195-206.

46. Limberg AA. Mathematical principles of local plastic procedures on the surface of the human body. Leningrad: Government Publishing House for Medical Literature; 1946.

47. Fricke JCG. Die Bildung der Augenlider (Blepheroplastik) nach Zerstorungen und. Dadurch
Hervorgebrachten Auswartswendungen Derselben. Hamburg: Perthes \& Besser; 1829.

48. Game J, Morlet N. Lateral canthal fixation using an oblique vertically orientated asymmetric periosteal transposition flap. Clin Exp Ophthalmol. 2007;35:204-7.

49. Leone CR Jr. Lateral canthal reconstruction. Ophthalmology. 1987;94:238-41.

50. Jones IS, Cooper WC. Lateral canthal reconstruction. Trans Am Ophthalmol Soc. 1973;71:296-302.

51. Bachelor EP, Jobe RP. The absent lateral canthal tendon: reconstruction using a Y graft or palmaris longus tendon. Ann Plast Surg. 1980;5:362-8.

52. Acikel C, Celikoz B, Yildiz TF. Y-shape hard palate mucoperiosteal graft and $\mathrm{V}-\mathrm{Y}$ advancement flap in the reconstruction of a combined defect involving lateral canthus and upper and lower eyelids. Ann Plast Surg. 2004 Jan;52(1):97-101.

53. Rathore DS, Chickadasarahilli S, Crossman R, Mehta $\mathrm{P}$, Ahluwalia HS. Full thickness skin grafts in periocular reconstructions: long-term outcomes. Ophthal Plast Reconstr Surg. 2014 Nov-Dec;30(6):517-20.

Open Access This chapter is licensed under the terms of the Creative Commons Attribution 4.0 International License (http://creativecommons.org/licenses/by/4.0/), which permits use, sharing, adaptation, distribution and reproduction in any medium or format, as long as you give appropriate credit to the original author(s) and the source, provide a link to the Creative Commons license and indicate if changes were made.

The images or other third party material in this chapter are included in the chapter's Creative Commons license, unless indicated otherwise in a credit line to the material. If material is not included in the chapter's Creative Commons license and your intended use is not permitted by statutory regulation or exceeds the permitted use, you will need to obtain permission directly from the copyright holder. 